DOE/ER/62300

Mechanisms, Chemistry, and Kinetics of Anaerobic Biodegradation of cis-Dichloroethene and Vinyl Chloride

Final Report - 09/15/1996 - 09/14/2000

\author{
P. L. McCarty \\ A. M. Spormann
}

December 2000

Work Performed Under Contract No. DE-FG07-96ER62300

For

U.S. Department of Energy

Office of Energy Research

Washington, DC

By

Stanford University

Stanford, CA 
DOE/ER/62300

MECHANISMS, CHEMISTRY, AND KINETICS OF ANAEROBIC BIODEGRADATION OF CIS-DICHLOROETHENE AND VINYL CHLORIDE

FINAL REPORT

09/15/1996 - 09/14/2000

P. L. McCarty

A. M. Spormann

December 2000

Work Performed Under Contract No. DE-FG07-96ER62300

Prepared for the

U.S. Department of Energy

Office of Energy Research

Washington, DC

Prepared by

Stanford University

Stanford, CA 
FINAL REPORT

\section{Mechanisms, Chemistry, and Kinetics of Anaerobic Biodegradation of cis-Dichloroethene and Vinyl Chloride}

\section{Principal Investigators:}

Perry L. McCarty, mccarty@ce.stanford.edu, telephone (650) 723-4131, fax (650) 725-9474 Department of Civil and Environmental Engineering, Stanford University, Stanford, California 94305-4020

Alfred M. Spormann, spormann@ce.stanford.edu, telephone (650) 723-3668

Department of Civil and Environmental Engineering, Stanford University, Stanford, California 94305-4020

\section{Research Staff:}

Zachary C. Haston, Bettina M. Rosner, and Yanru Yang Department of Civil and Environmental Engineering, Stanford University, Stanford, California 94305-4020

Project Number:

Contract Number:

DOE Contract Administrator:

Project Duration:
54666

DE-FG07-96ER62300

T. Wade Hillebrant

September 15, 1996 to September 14, 2000 


\section{TABLE OF CONTENTS}

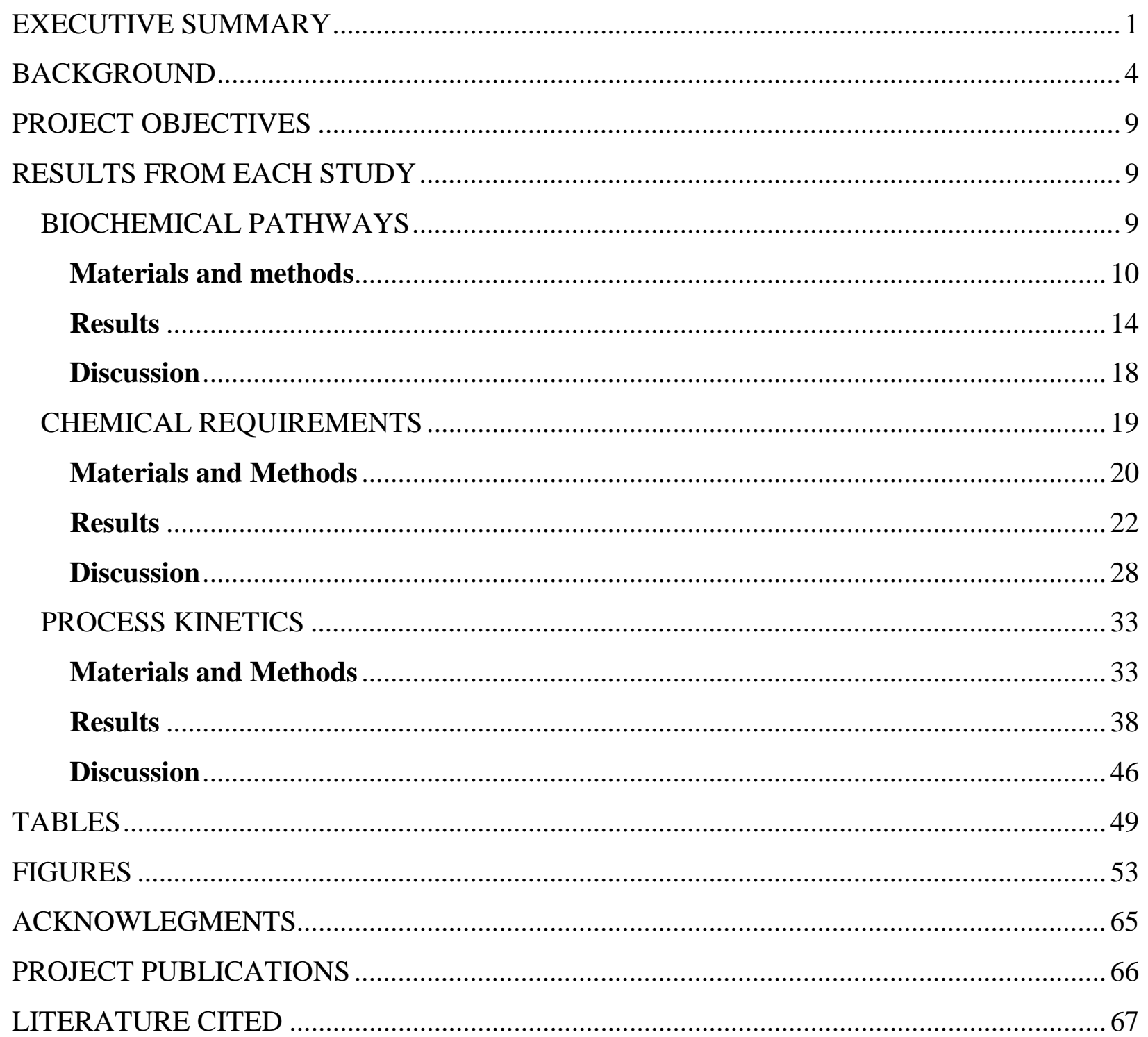




\section{EXECUTIVE SUMMARY}

The chlorinated solvents, trichloroethene (TCE) and tetrachloroethene (PCE) have been widely used. Through leakage and poor disposal practices, chlorinated solvents have contaminated groundwater, causing one of the most difficult and costly remediation problems in the country. Novel in-situ biological processes have shown good potential for destroying these contaminants. Anaerobic biological processes can result in PCE and TCE destruction through conversion to cisdichloroethene (cDCE) then to vinyl chloride (VC), and finally to ethene. Here, the chlorinated aliphatic hydrocarbons (CAHs) serve as electron acceptors in energy metabolism, requiring electron donors such as hydrogen from an external source. However, the conversions from cDCE to ethene tend to be slow. Also in some cultures, these conversions appear to be carried out by different microorganisms than the conversion of PCE to CDCE, although an organism that can carry out the whole process has been isolated by Maymo-Gatell et al. (1997). The purpose of this study was to learn more about the biochemistry of $\mathrm{CDCE}$ and $\mathrm{VC}$ conversion to ethene, to better understand the requirements for electron donors, and to determine factors affecting the rates of CAH degradation and organism growth.

The biochemistry of reductive dehalogenation of $\mathrm{VC}$ was studied with an anaerobic mixed culture enriched on VC. Ethene formation from VC increased exponentially at a rate of about $0.019 \mathrm{~h}^{-1}$. Using cell-free extracts of the mixed culture an apparent $\mathrm{K}_{\mathrm{m}}$ for $\mathrm{VC}$ was determined to be about $76 \mu \mathrm{M}$ and $\mathrm{V}_{\max }$ was about $28 \mathrm{nmol}$.min-1.mg protein-1. This enzymatic activity appears to be different from previously observed corrinoid-based reductive PCE dehalogenases because 1) the VC dehalogenase activity can not be inhibited with iodopropane, iodoethane, or iodomethane, inhibitors specific for corrinoid-catalyzed reactions, and 2) the higher chlorinated ethene PCE and TCE are reduced by cell-free extracts of this culture only at rates that are orders of magnitude lower than $\mathrm{VC}$ dehalogenation. In efforts towards purifying the $\mathrm{VC}$ dehalogenase, cells of the mixed culture that reduces VC to ethene were used. Cells were grown in anaerobic medium, harvested under anoxic conditions, broken by passage through a French pressure cell, and unbroken cells were separated from the cell extract by centrifugation. The VC dehalogenating activity was found associated with the membrane fraction of the cell extract and was partially released by treatment with zwitterionic detergents. Analysis of the proteins present 
in the active fraction revealed at least 3 protein bands. Several peptides were identified, some of which have the same molecular mass as the peptides from the highly enriched VC dehalogenase fraction.

In other studies on electron donor needs for dehalogenation of $\mathrm{CDCE}$ and $\mathrm{VC}$, competition for hydrogen was found to occur between the dehalogenators and other microorganisms such as methanogens and homoacetogens in a benzoate-acclimated dehalogenating methanogenic mixed culture. Results showed that the dehalogenators competed best against methanogens and homoacetogens when the hydrogen level was maintained between 2 and $11 \mathrm{nM}$. The $2 \mathrm{nM}$ hydrogen concentration represents the lower threshold value found here for this culture. The usefulness of this hydrogen range was further confirmed with both batch fed and continuously fed reactors. In batch studies, three times more ethene was produced from dehalogenation of cDCE using propionate than benzoate as electron donor, while benzoate produced three times more methane than propionate. A three times greater hydrogen utilization efficiency for dehalogenation was obtained with a semi-continuous CSTR than with batch reactors when benzoate was used as substrate because a constant hydrogen concentration in the appropriate range could be maintained with the CSTR. These results suggest different approaches that might be used to favor dehalogenators in competition with other microorganisms.

Comparative studies were conducted with benzoate, propionate, oleate, tetrabutyl orthosilicate (TBOS) and biomass as substrates that could be fermented to produce the hydrogen needed for dehalogenation of cDCE and VC. All five substrates supported dehalogenation. Sufficient calcium was required to precipitate oleate and thus reduce its toxicity to the dehalogenating microorganisms. More cDCE was dehalogenated with TBOS than with benzoate, although TBOS initially had an inhibitory effect. The most efficient dehalogenation was associated with biomass, $20 \%$ of which was used for dehalogenation, even higher than the $17 \%$ obtained with propionate. The advantages and disadvantages of these organic substances to be introduced into an aquifer as electron donors for in situ dehalogenation were examined in terms of efficiency of electron use for reductive dehalogenation and method and ease of introduction into the aquifer. 
Factors affecting the relative rates of destruction of the solvents and their intermediate products were evaluated. The maximum degradation rates $(k X)$ and half-velocity coefficients $\left(K_{S}\right)$ for these chlorinated ethenes used as electron acceptors in reductive dehalogenation with hydrogen in excess were examined using enrichment cultures grown on benzoate, hydrogen, and PCE. Initial dehalogenation rates were measured at various chlorinated ethene concentrations in batch studies. With $38 \mathrm{mg} / \mathrm{L}$ volatile suspended solids of this culture, the $k X$ and $95 \%$ confidence intervals for PCE, TCE, cis-dichloroethene (cDCE), and $\mathrm{VC}$ at $25^{\circ} \mathrm{C}$ were found to be $77 \pm 5$, $59 \pm 11,14 \pm 3$, and $13 \pm 3 \mu \mathrm{mol}$ per liter per day with $\mathrm{K}_{\mathrm{S}}$ values of $0.11 \pm 0.04,1.4 \pm 0.9$, $3.3 \pm 2.2$, and $2.6 \pm 1.9 \mu \mathrm{M}$, respectively. The lower maximum transformation rates and higher $\mathrm{K}_{\mathrm{S}}$ values for $\mathrm{CDCE}$ and $\mathrm{VC}$ partly explain why incomplete transformation of PCE and TCE often occurs in the field.

Studies using a mixed PCE-dehalogenating culture as well as the VC enrichment noted above for biochemical studies suggested that the same species was involved in both cDCE and VC dechlorination, and that $\mathrm{CDCE}$ and $\mathrm{VC}$ competitively inhibited each other's dechlorination rate. The inhibition coefficients for each were similar to their CDCE and VC half-velocity coefficients of 3.3 and $2.6 \mu \mathrm{M}$, respectively. Using a Monod-type growth model, the maximum specific growth rate on $\mathrm{VC}$ was determined to be $0.21 \pm 0.02 /$ day. Commercial cDCE was found to inhibit growth of the culture in proportion to the amount added. Biologically generated cDCE, however, exhibited no such adverse affect. Correcting for this inhibition, the maximum specific growth rate for $\mathrm{CDCE}$ dechlorination was $0.30 \pm 0.06 /$ day. 


\section{BACKGROUND}

The chlorinated solvents, trichloroethene (TCE) and tetrachloroethene (PCE) have been widely used by industry, the Department of Defense, and the Department of Energy for cleaning engines, clothes, and electronic components. Through leakage and improper disposal practices, these solvents have become the most frequent groundwater contaminants throughout the country, causing one of the most difficult and costly contamination problems for remediation. Most remediation approaches involve the extraction of contaminated groundwater and its cleanup at the surface through expensive physical and/or chemical methods. However, anaerobic biological processes have resulted in the natural destruction (intrinsic bioremediation) of the chlorinated solvents in some cases. Engineered in-situ biodegradative processes also offer much promise for complete destruction of the contaminants. However, the in situ biological processes are not adequately understood at the present and additional basic research on the biological processes involved is essential both for evaluating the true potential for intrinsic bioremediation at some sites and for reliable engineering of the process at others.

The biological anaerobic reduction of chlorinated aliphatic hydrocarbons (CAHs) such as tetrachloroethene (PCE) and trichloroethene (TCE) to cis-1,2-dichloroethene (CDCE), trans-1,2dichloroethene (tDCE), and vinyl chloride (VC) was reported in the 1980s (Barrio-Lage, et al., 1986; Parsons and B. Lage, 1985; Vogel and McCarty, 1985). Further reduction of PCE and its intermediates to ethene was reported by Freedman and Gossett (1989). In subsequent studies, the group of researchers at Cornell reported the conversion of PCE at concentrations as high as $55 \mathrm{mg} / \mathrm{l}$ to ethene (DiStefano, et al., 1991) with methanol being used as a primary substrate in the absence of methanogenesis. Here, about $70 \%$ of the methanol was converted to acetate, and about $30 \%$ was associated with the dechlorination reactions.

Several pure cultures of anaerobic bacteria were earlier found to reductively dehalogenate PCE

to TCE (Egli, Scholtz, Cook, \& Leisinger, 1988; Egli, Scholtz, Cook, Tschan, \& Leisinger, 1987; Fathepure \& Boyd,1988; Fathepure, Nengu, \& Boyd, 1987; Terzenbach \& Blaut, 1994). In these 
cases, the rate of PCE dehalogenation was slow. Only recently, the biochemical mechanisms of PCE transformation are beginning to emerge (see below).

Several pure cultures of microorganisms are now available that can also reduce PCE to cDCE (Holliger and Schumacher, 1994; Miller, et al., 1997; Neumann, et al., 1994; Scholz-Muramatsu, et al., 1995; Sharma and McCarty, 1996). Holliger $(1993 ; 1994 ; 1998)$ reported the isolation of a strictly anaerobic microorganism called Dehalobacter restrictus that utilizes hydrogen or formate as electron donors and PCE or TCE as electron acceptors in a catabolic process. This group showed that PCE reduction with hydrogen is coupled to proton translocation and generation of a proton gradient across the cytoplasmic membrane, providing good evidence that energy conservation can be coupled to PCE reduction to support growth (Schumacher and Holliger, 1996). The strictly anaerobic microorganism reported by Neumann et al. $(1995 ; 1996)$ and Scholz-Muramatsu et al. (1995) is called Dehalospirillum multivorans and uses PCE as terminal electron acceptor for catabolic oxidation of a variety of organic substrates, including pyruvate, lactate, ethanol, formate, and glycerol. Besides these organic compounds, D. multivorans also uses hydrogen as electron donor. When using $\mathrm{H}_{2}$ and PCE for energy conservation and acetate for cell carbon synthesis, growth yields were $1.4 \mathrm{~g}$ of cell protein per mole chloride released. When using pyruvate as an electron donor, a dechlorination rate of up to $220 \mu \mathrm{mol} / \mathrm{mg}$ protein/day and a doubling time of $2.5 \mathrm{~h}$ were obtained at an initial PCE concentration of 300 $\mu \mathrm{M}$. Concentrations higher than $300 \mu \mathrm{M}$ were inhibitory. Acetate and lactate were also end products of pyruvate fermentation. Dehalogenation did not occur with acetate as electron donor. The temperature optimum for this organism ranged from $25^{\circ}$ to $37^{\circ} \mathrm{C}$, with dechlorination completely inhibited at $42^{\circ} \mathrm{C}$. PCE dehalogenation had a narrow pH optimum between 7.0 and 7.5, and was inhibited at $\mathrm{pH} 6.0$ or 8.5 . This organism can alternatively use nitrate or fumarate as electron acceptors, but if present, they prevent dehalogenation, as does polysulfide. The dehalogenase is active in cell extracts, and was found to be soluble. Evidence suggests that the dehalogenase is constitutive.

As a comparison to dehalogenation rates, Tandoi et al. (1994) evaluated the kinetics of dehalogenation with a highly enriched mixed culture growing on methanol. They reported conversion of $0.55 \mathrm{mM}$ PCE to $\mathrm{VC}$ within $20 \mathrm{hr}$, or $4.6 \mu \mathrm{mol} \mathrm{PCE} / \mathrm{mg}$ cells/day in the presence 
of $1.6 \mathrm{mmol}$ methanol and $10 \mathrm{mg} / \mathrm{l}$ yeast extract. This rate is much lower than that for conversion of PCE to CDCE noted above. VC conversion to ethene did not occur until PCE was gone. In contrast, added VC was converted without delay in the absence of PCE. A mathematical model that they developed was consistent with $\mathrm{VC}$ conversion to ethene being delayed when other intermediates such as TCE or CDCE were present. No inhibition was observed with concentrations of up to $0.5 \mathrm{mM}$ of any of the chlorinated aliphatic hydrocarbons studied (PCE, TCE, cDCE, tDCE, 1,1-DCE, VC). Sharma and McCarty (1996), isolated the first reported facultative aerobic microorganism capable of converting PCE to $\mathrm{CDCE}$ from a contaminated site in Victoria, Texas. This rapidly-growing bacterium, termed strain MS-1, transforms PCE to $\mathrm{CDCE}$ at high rates in a defined growth medium. This transformation requires the absence of oxygen and nitrate, but does not require the highly reducing conditions associated with sulfate reduction or methanogenesis. With a suitable electron donor present, such as acetate, strain MS-1 will remove oxygen, then nitrate, and then PCE so that no other strain is necessary to bring about these conversions. Strain MS-1 can transform high concentrations of PCE (up to $1 \mathrm{mM}$ ) via TCE to cDCE. This is a much higher concentration tolerance than yet reported by others.

Only one pure culture that is capable of reducing CDCE to VC, or VC to ethene has been isolated (Maymo-Gatell et al., 1997), although there are numerous reports of such conversions in mixed cultures. The isolated microorganism, Dehalococcoides ethenogenes, is a strictly anaerobic microorganism that obtains energy for growth from complete conversion of PCE to ethene while using hydrogen as an electron donor and acetate as a source of carbon for cell synthesis. Besides acetate, vitamin $B_{12}$, and the nutrients present in digester supernatant liquid are required for growth. This requirement for additional growth factors was suggested to be the reason why dehalogenation to ethene appears to occur best in the presence of other microorganisms, which presumably produce these undefined growth factors. This microorganism is unusual because it is generally believed that $\mathrm{CDCE}$ and $\mathrm{VC}$ reduction is catalyzed by a group of microbes that is different from PCE and TCE dehalogenators. Notably, D. ethenogenes is able to grow via reductive dehalogenation of PCE, TCE and CDCE as catabolic electron acceptors, but not with $\mathrm{VC}$, although $\mathrm{VC}$ is reduced by this microorganism, presumably in a cometabolic process. 
Evidence available from the pure culture studies reported so far, indicates that reductive dehalogenation is coupled with energy conservation, an observation that suggests it may be an efficient mechanism for PCE and TCE dehalogenation in situ (Holliger and Schumacher, 1994; Schumacher and Holliger, 1996). Hydrogen may be the key intermediate in the anaerobic catabolism of organic matter that is used by the dehalogenating bacteria as an electron donor for the dehalogenation of cDCE to VC and VC to ethene (Fennel, et al., 1995). The hypothesis for hydrogen as key substrate suggests that the dehalogenating microorganisms would occupy a niche in an anaerobic system somewhat occupied by the hydrogen-consuming methanogens. Under methanogenic conditions, complex organic matter is fermented to simpler compounds, including short chain fatty acids and alcohols, which are then oxidized further to hydrogen, $\mathrm{CO}_{2}$ and acetate. The hydrogen is used as an electron donor by methanogens or acetogenic bacteria. Evidence is accumulating that the dehalogenating bacteria also compete for that hydrogen (Fennel et al., 1995; Yang and McCarty, 1998). It appears that hydrogen oxidation coupled with dehalogenation is much more favorable thermodynamically than when coupled with carbon dioxide reduction (methanogenesis) or sulfidogenesis (Vogel, et al., 1987). Another general observation is that (i) yeast extract or nutrients in digested sludge supernatant liquor is required to satisfy trace organic nutrient requirements, and (ii) an organic carbon source such as acetate is required for cell synthesis.

Some electron donors are more efficient than others at producing the hydrogen necessary for dehalogenation, and a fundamental question is why this is the case. One very plausible explanation is that various groups of microorganisms compete for hydrogen, and that dehalogenating microorganisms can survive better than others at very low hydrogen concentrations (Fennel et al., 1995; Smatlak, et al., 1996; Yang and McCarty, 1998). On this basis, slug addition of a compound such as formate, ethanol, or glucose is not as effective for dehalogenation as propionate because the former compounds are converted rapidly to hydrogen and acetate, and the latter is not. The rapid conversion is a result of more favorable thermodynamics with respect to hydrogen formation. Such rapid conversion places hydrogen in a concentration range where methanogens and sulfate reducers can compete effectively with dehalogenators. However, with benzoate, for example, hydrogen production is slower and consistent with a very low concentration as dictated by thermodynamics. With a low and 
continuous supply of hydrogen, the dehalogenators are at a competitive advantage. This hypothesis is consistent with experimental results (Fennell and Gossett, 1998; Fennell, et al., 1997; Yang and McCarty, 1998). This is the hypothesis upon which the experimental investigations reported here are based.

The biochemistry of reductive dehalogenation is beginning to emerge. Gantzer and Wackett (1991) found that vitamin $\mathrm{B}_{12}$ by itself can reductively dehalogenate $\mathrm{PCE}$ in vitro with $\mathrm{Ti}^{3+}$ as the reductant. Interestingly, the rate of vitamin $\mathrm{B}_{12}$-catalyzed dehalogenation of chloroethenes is inversely correlated with the number of chlorine substituents; the rate of PCE dechlorination is at least 3 orders of magnitude higher than the rate of $\mathrm{VC}$ dechlorination. Cell-free extracts of homoacetogenic bacteria with a relatively high corrinoid content, such as Sporomusa ovata, catalyze the reductive dehalogenation of PCE to TCE (Terzenbach and Blaut, 1994). COreduced carbon monoxide dehydrogenase, a corrinoid-containing enzyme from Methanosarcina thermophila, has been shown to reductively dechlorinate TCE to ethene (Jablonski and Ferry, 1992). All PCE dehalogenases studied to date in detail are corrinoid containing enzymes (Magnuson, et al., 1998; Miller et al., 1997; Neumann et al., 1996; Schumacher and Holliger, 1996), see also Holliger, Wohlfarth and Diekert (1998) for review). The purified PCE dehalogenase of D. multivorans was shown to contain $1 \mathrm{~mol}$ of corrinoid and about $8 \mathrm{~mol}$ of iron and 8 mol of acid-labile sulfur per mol of enzyme (Neumann et al., 1996). The purified PCE dehalogenases of Desulfitobacterium strain PCE-S and of D. restrictus also contain $1 \mathrm{~mol}$ of corrinoid per mol of enzyme (Miller et al., 1997; Schumacher and Holliger, 1996). The PCEreductive dehalogenase and the TCE-reductive dehalogenase from Dehalococcoides ethenogenes have been shown to be light-reversibly inhibited by iodoethane and iodopropane, respectively, implying that a corrinoid is involved in reductive dehalogenation in this microorganism as well (Magnuson et al., 1998). With the exception of the PCE dehalogenase from D. multivorans, the PCE and TCE reductive dehalogenases are membrane-associated enzymes. PCE-reductive dehalogenation appears to be involved in energy conservation in microorganisms such as $D$. restrictus (Holliger et al., 1993; Holliger and Schumacher, 1994; Holliger et al., 1998) and in D. multivorans (Neumann et al., 1994; Scholz-Muramatsu et al., 1995), and possibly also in strain PCE-S and others. The gene encoding for PCE dehalogenase from D. multivorans was cloned 
and sequenced, but did not show any significant similarity to sequences of known proteins in the data base (Neumann et al., 1996).

\section{PROJECT OBJECTIVES}

As previous studies indicate, rates of reduction of PCE and TCE to CDCE are high and the need for electron donor addition for the reactions is small. However, the subsequent reduction of $\mathrm{cDCE}$ to $\mathrm{VC}$, and then of $\mathrm{VC}$ to the harmless end product, ethene, is much slower and only recently has a pure culture been reported that is capable of reducing $\mathrm{CDCE}$ to $\mathrm{VC}$ or $\mathrm{VC}$ to ethene. There are numerous reports of such conversions in mixed cultures. Because of the importance of the conversions of $\mathrm{CDCE}$ and VC to ethene for successful bioremediation of TCE and PCE contaminated sites, and the lack of adequate information about these conversions, the chemistry, kinetics, and biochemistry of these steps is where basic research is most in need, and thus the subject of this study.

The objectives of this study then are to (1) determine the biochemical pathways for reductive dehalogenation of $\mathrm{CDCE}$ and $\mathrm{VC}$, including identification of the enzymes involved, (2) determine the chemical requirements, especially the type and quantity of electron donors needed by the microorganisms for reductive dehalogenation, and (3) evaluate the kinetics of the process with respect to effect of concentration of both the electron donors and the electron acceptors (cDCE and VC).

\section{RESULTS FROM EACH STUDY}

\section{BIOCHEMICAL PATHWAYS}

Investigators: B. M. Rosner and A. M. Spormann

This study was directed towards a better understanding of the biochemistry of anaerobic conversion of VC into ethene. Detailed results of these studies are contained in the publication: Rosner, B, McCarty, P. L., and Spormann, A. M. (1997), "In Vitro Studies on Reductive Vinyl 
Chloride Dehalogenation by an Anaerobic Mixed Culture." Appl. Environ. Microbiol., 63 (11):4139-4144. A summary of results follows.

Reductive dehalogenation of VC was studied with an anaerobic mixed culture enriched on VC. In growth experiments, ethene formation from $\mathrm{VC}$ increased exponentially at a rate of about $0.019 \mathrm{~h}^{-1}$. Reductive $\mathrm{VC}$ dehalogenation was measured in vitro using cell-free extracts of the mixed culture. The apparent $\mathrm{K}_{\mathrm{m}}$ for $\mathrm{VC}$ was determined to be about $76 \mu \mathrm{M} ; \mathrm{V}_{\max }$ was about 28 nmol.min-1.mg protein-1. The VC dehalogenating activity was membrane-associated. Propyl iodide had an inhibitory effect on the VC dehalogenating activity in the in vitro assay. However, this inhibition could not be reversed by illumination as is generally the case when vitamin B-12 is the transforming factor involved. Cell-free extracts also catalyzed the reductive dehalogenation of $\mathrm{CDCE}$ and, at a much lower rate, TCE. PCE was not transformed. The results indicate that the $\mathrm{VC}$ dehalogenating microorganism(s) in the enrichment culture could also dehalogenate cDCE, but not the more chlorinated ethenes.

\section{Materials and methods}

Growth of the culture. An anaerobic mixed bacterial culture was originally obtained from a tetrachloroethene (PCE)-contaminated site in Victoria, TX. The culture has been maintained in our laboratory for several years in the presence of PCE. To enrich for vinyl chloride (VC) dehalogenating microorganisms, the culture was repeatedly grown anaerobically in the presence of $\mathrm{VC}$ in mineral salts medium containing $17 \mathrm{mM} \mathrm{NaCl}, 2 \mathrm{mM} \mathrm{MgCl}_{2}, 1.5 \mathrm{mM} \mathrm{KH}_{2} \mathrm{PO}_{4}, 5 \mathrm{mM}$ $\mathrm{NH}_{4} \mathrm{Cl}, 7 \mathrm{mM} \mathrm{KCl}, 1 \mathrm{mM} \mathrm{CaCl}_{2}, 30 \mathrm{mM} \mathrm{NaHCO}_{3}$, and $1 \mathrm{mM} \mathrm{Na}_{2} \mathrm{~S}$. In addition, the medium was amended with $1 \mathrm{mM}$ acetate, $0.001 \%$ to $0.02 \%(\mathrm{w} / \mathrm{v})$ yeast extract, 1 or $10 \mathrm{mM} 2-$ bromoethanesulfonic acid, trace element solution (SL 10), selenite-tungstate solution, vitamins (a seven-vitamins solution plus $2 \mu \mathrm{g}$ folic acid x $2 \mathrm{H}_{2} \mathrm{O}$ per liter, $5 \mu \mathrm{g}$ riboflavin per liter, $5 \mu \mathrm{g}$ D,L-6,8 thioctic acid per liter) and resazurin $(1 \mathrm{mg} / \mathrm{L})$. After autoclaving, the medium was cooled under $\mathrm{N}_{2} / \mathrm{CO}_{2}(80 \% / 20 \%)$, and the $\mathrm{pH}$ was adjusted to 7.2 to 7.4 . The headspace of the mediacontaining bottles (1.2 L headspace, $1 \mathrm{~L}$ liquid) was exchanged with $\mathrm{H}_{2} / \mathrm{CO}_{2}(70 \% / 30 \%)$. The bottles were brought into an anaerobic glove box $\left(10 \% \mathrm{H}_{2}, 10 \% \mathrm{CO}_{2}, 80 \% \mathrm{~N}_{2}\right)$ and sealed with polytetrafluoroethylene (PTFE) Mininert valves (Alltech, Deerfield, IL). Thus, the final $\mathrm{H}_{2^{-}}$ 
concentration in the headspace of the medium bottles was between 10 and 70\%. Gaseous VC was added corresponding to an initial concentration in the liquid of 50 to $150 \mu \mathrm{M}$. The culture was incubated in the anaerobic glove box at room temperature.

Preparation of cell-free extracts. Cells of the mixed culture were harvested anaerobically at the end of the logarithmic phase of ethene formation by centrifugation $\left(13,000 \mathrm{x} g, 20 \mathrm{~min}, 4^{\circ} \mathrm{C}\right)$. The pellet was washed once with anoxic $100 \mathrm{mM}$ Tris-HCl (pH 8.0) and resuspended in about 2 $\mathrm{mL}$ of this buffer. Cells were broken anoxically by four passages through a French press at 138 MPa. Unbroken cells and cell debris were removed by centrifugation $\left(27,000 \mathrm{x} g, 10 \mathrm{~min}, 4^{\circ} \mathrm{C}\right)$. The supernatant was defined as cell-free extract. The cell-free extract was stored under nitrogen at $-20^{\circ} \mathrm{C}$.

Fractionation of cell-free extract. The cell-free extract was separated into the membrane and the cytoplasmic fraction by ultracentrifugation $\left(200,000 \mathrm{x} g, 2\right.$ hours, $\left.6^{\circ} \mathrm{C}\right)$. The membrane fraction was resuspended in anoxic $100 \mathrm{mM}$ Tris- $\mathrm{HCl}(\mathrm{pH} 8.0)$.

In vitro assay for reductive dehalogenation. Assays for quantifying the reductive VC dehalogenating activity in cell-free extracts of the mixed culture were performed in $5 \mathrm{~mL}$-glass vials sealed with PTFE Mininert valves. The anoxic standard assay mixture (final volume $1 \mathrm{~mL}$ ) contained $100 \mathrm{mM}$ Tris- $\mathrm{HCl}$ (pH 8.5), $0.5 \mathrm{mM}$ methyl viologen, $1 \mathrm{mM}$ titanium(III) citrate, and cell-free extract (15-90 $\mu \mathrm{g}$ protein). The reaction was started by addition of gaseous $\mathrm{VC}$ corresponding to an initial liquid concentration of about $0.4 \mathrm{mM}$. The reaction vials were incubated at room temperature in an anaerobic glovebox while agitated on an orbital shaker. At defined time intervals, headspace samples $(250 \mu \mathrm{L})$ were taken and analyzed for ethene by gas chromatography (see below). Concentrations of volatile chlorinated compounds were calculated using published data for Henry's law constants.

Experiments testing for reductive dehalogenation of cis-1,2-dichloroethene (cis-DCE), trichloroethene (TCE), or PCE were conducted as described above. The chlorinated compounds were added from saturated aqueous stock solutions that had been prepared in anoxic $100 \mathrm{mM}$ Tris- $\mathrm{HCl}(\mathrm{pH}$ 8.5) at least one day before the experiment. After addition of the stock solution to 
the assay, the mixture was equilibrated for about one hour before other components of the assay were added. The reaction was started by addition of cell-free extract. At defined time intervals, headspace samples $(250 \mu \mathrm{L})$ were taken and analyzed for chlorinated aliphatic compounds and ethene by gas chromatography (see below).

For determination of the $\mathrm{pH}$-optimum, assays were performed in anoxic buffer mixtures of constant ionic strength consisting of $100 \mathrm{mM}$ Tris, $50 \mathrm{mM}$ 2-(N-morpholino) ethanesulfonic acid (MES), and $50 \mathrm{mM}$ acetic acid.

$\mathrm{K}_{\mathrm{m}}$ and $\mathrm{V}_{\max }$ values were calculated from non-linear least squares fits of experimental data using the computer program SCIENTIST (MicroMath Scientific Software, Salt Lake City, UT).

Determination of other enzyme activities. Hydrogenase activity was measured in cell-free extracts in a photometric assay with methyl viologen as the electron acceptor. ATPase activity was measured using a coupled photometric enzyme assay with pyruvate kinase and lactate dehydrogenase. Malate dehydrogenase activity was measured in a photometric assay.

Inhibitor studies. Propyl iodide was tested as an inhibitor of reductive VC dehalogenation by cell-free extracts. Propyl iodide inhibits corrinoid-dependent reactions by alkylating the cobalt cation of the corrinoid in its reduced form. This inhibition can be reversed by illumination of the assay mixture. Inhibitor experiments were performed in the standard in vitro assay mixture described above, except the concentration of titanium(III) citrate was increased to $2 \mathrm{mM}$. The cell-free extract was incubated with propyl iodide (10 to $100 \mu \mathrm{M}$ in the assay; stock solution in ethanol) for $10 \mathrm{~min}$ in the dark before the reaction was started by addition of methyl viologen and VC. To test whether the inhibition of VC dehalogenating activity by propyl iodide was reversible, the assay mixture was illuminated for 2 min with a slide projector lamp after incubation of the cell-free extract with propyl iodide, and subsequently analyzed for VC dehalogenating activity. To test the effectiveness of propyl iodide as a corrinoid-specific inhibitor under these assay conditions, the inhibition of vitamin $\mathrm{B}_{12}$-catalyzed reductive dehalogenation of PCE to TCE by propyl iodide was measured. These control experiments were conducted as described above, except Vitamin $\mathrm{B}_{12}$ (cyanocobalamin) $(20 \mu \mathrm{M})$ and PCE (about 
$30 \mu \mathrm{M}$ ) were added to the assay mixture. The formation of TCE from PCE was monitored by gas chromatography (photoionization detector, see below). Experiments with methyl iodide and ethyl iodide were performed in the same manner.

Intrinsic factor (Sigma, St. Louis, MO), a compound known to bind vitamin $\mathrm{B}_{12}$ was tested as a potential inhibitor of reductive $\mathrm{VC}$ dehalogenation. One unit of intrinsic factor will bind one nanogram of vitamin $B_{12}$. The concentration of vitamin $B_{12}$ in the cell-free extract was estimated using data published for anaerobic bacteria with a high corrinoid content, Acetobacterium woodii (1.3 nmol vitamin $\mathrm{B}_{12}$ per $\mathrm{mg}$ protein) and Methanosarcina barkeri (5 nmol corrinoid per $\mathrm{mg}$ protein). The assay mixture including cell-free extract was incubated with intrinsic factor for 15 min before the reaction was started by addition of VC.

To study the effect of cyanide on VC dehalogenation, the cell-free extract was incubated in the assay mixture in the presence of different potassium cyanide concentrations $(10 \mu \mathrm{M}, 100 \mu \mathrm{M}$, and $1000 \mu \mathrm{M}$ ) for $15 \mathrm{~min}$ before $\mathrm{VC}$ was added to start the reaction.

Gas chromatography. Ethene, ethane, and methane were analyzed with a Hewlett-Packard 5730A gas chromatograph (Hewlett-Packard, Palo Alto, CA) equipped with a flame ionization detector and a packed 60/80 Carbosieve G column (5'x 1/8', Supelco, Bellefonte, PA). Analyses were isothermal at $90^{\circ} \mathrm{C}$. Peak integration was performed with a Spectra-Physics model SP 4050 plotter (Spectra-Physics, Sunnyvale, CA). Compounds were identified by their retention times using external standards of ethene, ethane, and methane in nitrogen (Alltech).

VC, cis-DCE, TCE, and PCE, were analyzed with a Carlo Erba Fractovap 2900 series gas chromatograph (Carlo Erba Strumentazione, Milano, Italy) equipped with a photoionization detector as described elsewhere. Analyses were isothermal at $60^{\circ} \mathrm{C}$ or $40^{\circ} \mathrm{C}$. Compounds were identified by comparison of their retention times to external gaseous standards. To analyze the chlorinated compounds, ethene, ethane, and methane simultaneously, a Hewlett-Packard 5890 Series II gas chromatograph equipped with a flame ionization detector (Hewlett-Packard) and a GS-Q fused silica capillary column (30 m length, $0.53 \mathrm{~mm}$ inner diameter (J\&W Scientific)) was used. Analyses were performed using a temperature program $\left(40^{\circ} \mathrm{C}\right.$ to $\left.190^{\circ} \mathrm{C}\right)$. 
Optical density. Optical density was measured at $600 \mathrm{~nm}$ with a Spectronic model 20 D singlebeam spectrophotometer (Milton Roy, Rochester, NY).

Protein determination. Protein was determined using a commercially available dye-binding assay (Bio-Rad Laboratories, Hercules, CA). Bovine serum albumin was used as a standard. Cell suspensions were hydrolyzed in $10 \mathrm{M} \mathrm{NaOH}$ before protein determination.

Chemicals and gases. Titanium(III) citrate was prepared anoxically. Chemicals were of highest purity and were obtained from Sigma (St. Louis, MO), Aldrich (Milwaukee, WI), or Fluka (Milwaukee, WI). Gases were obtained from Altair (San Carlos, CA). Vinyl chloride (> 99.5\% purity) was obtained from Fluka.

\section{Results}

Growth and ethene formation from vinyl chloride. Anaerobic dehalogenation of vinyl chloride (VC) was studied in a mixed bacterial culture. After several transfers of the culture, grown in the presence of $\mathrm{VC}$, the enrichment culture contained four morphologically different, as yet unspecified types of microorganisms. According to experiments with Eubacteria-, and Archaea-specific fluorescent 16S rRNA probes, about $90 \%$ of the microorganisms in the culture were related to Eubacteria and about $10 \%$ consisted of Archaea. Work to isolate a pure culture is in progress.

The increase in optical density and ethene formation in the mixed culture is depicted in Figure 1. Optical density $\left(\mathrm{OD}_{600}\right)$ increased non-exponentially to 0.06 . In contrast, ethene formation increased exponentially at a rate of $0.019 \pm 0.001 \mathrm{~h}^{-1}$, corresponding to an apparent doubling time of approximately $36 \pm 2 \mathrm{~h}$. The amount of cell protein of a 1L-culture in the late logarithmic phase of ethene formation was about $2.6 \mathrm{mg}$. Thus, the specific in vivo ethene formation rate was about $30 \mathrm{nmol} \cdot \mathrm{min}^{-1} \cdot \mathrm{mg}$ protein ${ }^{-1}$. When the yeast extract concentration in the growth medium was increased to $0.02 \%(\mathrm{w} / \mathrm{v})$, the maximal optical density was slightly higher $\left(\mathrm{OD}_{600}=0.08\right)$; however, the ethene formation rate did not change. Cultures grown in the absence of VC reached 
the same maximal optical density as cultures grown in the presence of VC. However, ethene was formed only when VC was present in the growth medium. The actual electron donor for in vivo reductive VC dehalogenation is presently unknown. Possible electron donors in the growth medium include hydrogen, acetate, and yeast extract.

Reductive dehalogenation of VC in cell-free extracts. Cell-free extracts of the mixed culture catalyzed the reductive dehalogenation of VC. Under standard assay conditions, the concentration of ethene formed from VC increased linearly for at least $20 \mathrm{~min}$ at a specific rate of about 20 to $30 \mathrm{nmol} \cdot \mathrm{min}^{-1} \cdot \mathrm{mg}$ protein $^{-1}$. No ethene formation was detected in heat-treated cellfree extracts or in the absence of VC. In vitro reductive VC dehalogenation was dependent on the presence of titanium(III) citrate and reduced methyl viologen. When titanium(III) citrate was omitted from the assay mixture, the rate of VC dehalogenation was one to two orders of magnitude lower. An internal electron donor present in the cell-free extract was able to reduce methyl viologen, as indicated by a color change from colorless to blue. Since the experiments were carried out in the presence of about $10 \%$ hydrogen, methyl viologen may have been reduced by hydrogenase activity of the cell-free extract. This would explain the low rate of VC dehalogenation observed in the absence of titanium(III) citrate. Cell-free extracts of the mixed culture contained hydrogenase activity at a specific rate of about $3 \mu \mathrm{mol} \cdot \mathrm{min}^{-1} \cdot \mathrm{mg}^{\mathrm{protein}}{ }^{-1}$.

In the absence of methyl viologen, the VC dehalogenating activity was decreased by 80 to $90 \%$. Titanium(III) citrate-reduced benzyl viologen (0.2 mM), NADH (5 mM), and NADPH (5 mM) were tested as alternative electron donors for in vitro VC dehalogenation. With reduced benzyl viologen, the $\mathrm{VC}$ dehalogenation was $10 \%$ of the activity measured with reduced methyl viologen. No ethene formation was observed with NADH or NADPH. Exposure of cell-free extract to air for 20 min reduced the activity by about $50 \%$. Only about $1 \%$ of the VC dehalogenating activity was measured in extracts of cells that had been grown in the absence of VC.

The rate of VC dehalogenation was linearly dependent on the protein concentration (Figure 2). With increasing initial VC concentration, the rate of ethene formation increased according to Michaelis-Menten kinetics. The apparent $\mathrm{K}_{m}$ value for $\mathrm{VC}$ was determined to be about $76 \mu \mathrm{M}$, 
and $\mathrm{V}_{\max }$ was about $28 \mathrm{nmol} \cdot \mathrm{min}^{-1} \cdot \mathrm{mg}$ protein $^{-1}$. To ascertain the $\mathrm{pH}$-optimum for $\mathrm{VC}$ dehalogenation, the activity was tested at constant ionic strength in a range from $\mathrm{pH} 4.0$ to 10.0 in $0.5 \mathrm{pH}$-unit steps. The $\mathrm{pH}$ optimum was found to be at $\mathrm{pH} 8.5$ (100\% activity). The VC dehalogenating activity was $1 \%$ at $\mathrm{pH} 5.0,50 \%$ at $\mathrm{pH} 7.0$, and $50 \%$ at $\mathrm{pH} 10.0$.

To localize reductive VC dehalogenating activity, the cell-free extract was separated into the membrane and the cytoplasmic fraction. Of the total VC dehalogenating activity, $63 \%$ was found in the membrane fraction and $7 \%$ in the cytoplasmic fraction (Table 1). This suggests that the VC dehalogenating activity is membrane-associated. ATPase, an enzyme known to be membrane-bound, was found in the membrane fraction ( $46 \%$ of total activity) and in the cytoplasmic fraction (37\% of total activity). In contrast, malate dehydrogenase, a cytoplasmic enzyme, was predominantly found in the cytoplasmic fraction (66\% of total activity).

Inhibitor studies. To investigate whether a corrinoid was involved in reductive VC dehalogenation, the effect of propyl iodide was studied. Propyl iodide at a low concentration (10 $\mu \mathrm{M})$ reduced the rate of $\mathrm{VC}$ dehalogenation by 50 to $60 \%$. However, this inhibition could not be reversed by illumination. Higher concentrations of propyl iodide, methyl iodide, or ethyl iodide $(100 \mu \mathrm{M})$ reduced the in vitro $\mathrm{VC}$ dehalogenation rate by 40 to $75 \%$ (Figure 3), by about $60 \%$, and by about $95 \%$, respectively. Again, reactivation of the $\mathrm{VC}$ dehalogenation activity by illumination was never observed. To confirm that propyl iodide could specifically inactivate vitamin $\mathrm{B}_{12}$ in these assays, vitamin $\mathrm{B}_{12}$-catalyzed tetrachloroethene (PCE) dehalogenation in the presence of propyl iodide was studied as a control. PCE dehalogenation by vitamin $\mathrm{B}_{12}$ was completely inhibited by $50 \mu \mathrm{M}$ propyl iodide. This inhibition was reversed by illumination. Cellfree extracts from the mixed culture alone did not catalyze reductive PCE dehalogenation (see below).

To examine if unbound vitamin $\mathrm{B}_{12}$ might be involved in reductive VC dehalogenation, the effect of intrinsic factor was tested. In an assay with low amounts of cell-free extract (30 $\mu \mathrm{g}$ protein) that presumably contained about 50 to $200 \mathrm{ng}$ vitamin $\mathrm{B}_{12}$, the VC dehalogenating activity was not reduced in the presence of $90 \mathrm{U}$ of intrinsic factor. This amount of intrinsic factor would have been sufficient to bind $90 \mathrm{ng}$ of vitamin $\mathrm{B}_{12}$. 
We also studied the effect of cyanide, an inhibitor of transition metal containing enzymes, on in vitro VC dehalogenation. Potassium cyanide at low concentrations significantly affected the VC dehalogenating activity. The activity was reduced by 30,80 , and $98 \%$, in the presence of $10 \mu \mathrm{M}$, $100 \mu \mathrm{M}$, and $1 \mathrm{mM}$ cyanide, respectively. This suggests that a transition-metal cofactor may be involved in reductive VC dehalogenation.

Reductive dehalogenation of higher chlorinated aliphatic ethenes. We tested whether cis1,2-dichloroethene (cis-DCE), trichloroethene (TCE), and PCE could be reductively dehalogenated by cell-free extracts of the mixed culture. As shown in Figure 4a, cis-DCE was dehalogenated to $\mathrm{VC}$ and ethene. At comparable initial concentrations of the halogenated ethenes $(150$ to $300 \mu \mathrm{M})$, the specific rate of VC formation from ${\text { cis-DCE was } 18 \mathrm{nmol} \cdot \mathrm{min}^{-1} \cdot \mathrm{mg} \text { protein }}^{-}$ 1, which was similar to the specific rate of ethene formation from VC $\left(17 \mathrm{nmol} \cdot \mathrm{min}^{-1} \cdot \mathrm{mg}\right.$ protein $\left.{ }^{1}\right)$. However, the specific rate of ethene formation from cis-DCE was about 20 times lower than the specific rate of ethene formation from VC. With cis-DCE concentrations increasing from 50 $\mu \mathrm{M}$ to $750 \mu \mathrm{M}$, the VC formation rate from cis-DCE increased according to Michaelis-Menten kinetics (Figure 4b). The apparent $\mathrm{K}_{m}$ for cis-DCE was about $190 \mu \mathrm{M}$, and the apparent $\mathrm{V}_{\max }$ was about $26 \mathrm{nmol} \cdot \mathrm{min}^{-1} \cdot \mathrm{mg}$ protein ${ }^{-1}$. Remarkably, the specific ethene formation rate from $\mathrm{cis}^{\mathrm{DCE}}$ decreased with increasing cis-DCE concentrations (Figure 4b) which resulted in an accumulation of VC during cis-DCE dehalogenation.

With TCE as electron acceptor in the dehalogenation assay, the formation of trace amounts (less than $10 \mathrm{nmol}$ each after 1 hour of incubation) of cis-DCE, VC, and ethene was observed. When PCE was tested as the substrate in the reductive dehalogenation assay, it was transformed only at an extremely low rate. About $1 \mathrm{nmol}$ of TCE was measured during a 3-hour experiment; formation of cis-DCE, VC or ethene was not detected.

\section{Discussion}

A major interest of this study was to determine whether the characteristics of the vinyl chloride 
(VC) dehalogenating activity were similar to those of known tetrachloroethene (PCE) and trichloroethene (TCE) dehalogenating enzymes and coenzymes. To our knowledge, no studies on enzymatic processes involved in reductive VC dehalogenation have been reported previously.

Two observations suggest that the reductive $\mathrm{VC}$ dehalogenating activity catalyzed by cell-free extracts of this mixed culture may be different from previously reported reductive PCE dehalogenases. First, a corrinoid does not appear to be involved in reductive VC dehalogenation. Propyl iodide, methyl iodide and ethyl iodide had no specific inhibitory effect on the VC dehalogenating activity. Although partial inactivation was observed, the inhibition could not be reversed upon illumination. Control experiments with vitamin $\mathrm{B}_{12}$ demonstrated that propyl iodide, methyl iodide and ethyl iodide were effective in reversibly inhibiting corrinoid-dependent dehalogenation under these assay conditions. The decreased VC dehalogenating activity may have been caused by an unspecific alkylation of sulfhydryl groups. In cell-free extracts or cell suspensions of Dehalospirillum multivorans and Dehalobacter restrictus, propyl iodide inhibited the corrinoid-dependent PCE transformation. After exposure to light, the PCE dehalogenating activity was restored.

Second, the rate of $\mathrm{VC}$ dehalogenation was several orders of magnitude higher than rates determined for VC dehalogenation catalyzed by transition-metal containing coenzymes such as vitamin $\mathrm{B}_{12}$, coenzyme $\mathrm{F}_{430}$ from methanogens, and hematin. Based exclusively on the estimated vitamin $\mathrm{B}_{12}$ content of the cell-free extract (1.3 to $5 \mathrm{nmol}$ vitamin $\mathrm{B}_{12} \cdot \mathrm{mg}_{\text {protein }}{ }^{-1}$ ), the rate of VC dehalogenation would be on the order of $10 \mathrm{fmol} \cdot \mathrm{min}^{-1}$ when calculated as described by Wackett and Schanke. The dehalogenation rates by the transition-metal coenzymes decreased drastically with decreasing degree of halogenation of the alkenes. In contrast, cell-free extracts of the VC dehalogenating culture studied here, catalyzed VC and cis-1,2-dichloroethene (cis-DCE) dehalogenation at similar high rates $\left(\mathrm{V}_{\max }=28\right.$ and $26 \mathrm{nmol} \cdot \mathrm{min}^{-1} \cdot \mathrm{mg}$ protein ${ }^{-1}$, respectively), whereas the dehalogenation rates for the higher chlorinated alkenes TCE and PCE were one or two orders of magnitude lower.

The differences between the VC and cis-DCE dehalogenating activity described here and the previously reported PCE and TCE dehalogenating activity may suggest that complete 
dehalogenation of PCE to ethene is a two-step process in vivo. The original mixed culture, from which this VC dehalogenating enrichment culture was derived, was capable of complete dehalogenation of PCE to ethene. Earlier, an organism was isolated from that original mixed culture (strain MS-1) which reduces PCE to cis-DCE. With one exception, other pure cultures capable of PCE dehalogenation form cis-DCE as the transformation end product as well.

It could not be determined whether reductive $\mathrm{VC}$ dehalogenation is involved in energy conservation. However, the VC dehalogenating activity was found to be membrane-associated (Table 1) and reductive VC dehalogenation is a thermodynamically favorable process with hydrogen $\left(\Delta \mathrm{G}^{0,}=-149 \mathrm{~kJ} / \mathrm{mol} \mathrm{VC}\right)$ or acetate $\left(\Delta \mathrm{G}^{0,}=-122 \mathrm{~kJ} / \mathrm{mol} \mathrm{VC}\right)$ as the electron donor. Therefore, it is possible that VC reduction may be coupled to electron transport phosphorylation. Dehalogenases of organisms capable of reductive dechlorination in a respiratory process have been reported to be membrane-associated, with the exception of PCE dehalogenase of $D$. multivorans. The physiological electron donor for reductive $\mathrm{VC}$ dehalogenation is not yet known. The in vitro and in vivo rates for $\mathrm{VC}$ dehalogenation were similar, which suggests that reduced methyl viologen could function as a suitable substitute for the physiological electron donor. Reduced benzyl viologen, NADH, and NADPH were not effective as electron donors. This was also described for dehalogenases of PCE dehalogenating microorganisms. Reduced menaquinone has been suggested as the physiological electron donor for PCE dehalogenase of $D$. restrictus.

\section{CHEMICAL REQUIREMENTS}

Investigators: Y. Yang and P. L. McCarty

These studies were directed towards finding the hydrogen concentration range and threshold level that favors dehalogenators in competition with other possible hydrogen utilizing microorganisms within a methanogenic mixed culture. More detailed findings of these studies can be found in the publications: Yang, Y. and McCarty, P. L (1998), "Competition for Hydrogen within a Chlorinated Solvent Dehalogenating Mixed Culture," Environmental Science 
\& Technology, 32(22), 3591-3597, and Yang, Y. and McCarty, P. L., (1999), "Response to 'Comment on 'Competition for Hydrogen within a Chlorinated Solvent Dehalogenating Anaerobic Mixed Culture'," Environmental Science \& Technology, 33(12), 2128.

Also investigated were suitable substrates for biological hydrogen generation to satisfy the needs for dehalogenation while reducing competition for the hydrogen produced. Detailed results of these studies can be found in the publication: Yang, Y. and McCarty, P. L. (2000), "Biomass, Oleate, and Other Possible Substrates for Chloroethene Reductive Dehalogenation," Bioremediation Journal, 4(2) 125-133. A summary of results and findings from these studies are given below.

\section{Materials and Methods}

Chemicals. Liquid PCE, TCE and 1,2-cDCE (Aldrich Chem. Co., Milwaukee, WI) were used for preparing stock feed solutions and analytical standards. VC, ETH and methane gases (99+\%, Scott Specialty Gases, Alltech Associates, Inc., Deerfield, IL) were used as analytical standards. Benzoate (sodium salt, 99\%, Aldrich Chem. Co.), hydrogen (99.99\%, Scott Specialty Gases), and acetate (analytical reagent, J. T. Baker Chemical Co., Phillipsburg, NJ) were used as electron donors and to develop analytical standards. Yeast extract (Difco Laboratories, Detroit, MI) was used as a nutrient source.

Culture and growth medium. Digested sludge was collected from a municipal wastewater treatment plant and used directly for an initial comparative evaluation of the hydrogen threshold for methanogenesis. For all subsequent evaluations a dehalogenating source culture was developed in a closed continuously stirred tank reactor (CSTR) (total volume 4.31, liquid volume 3.61 ) initially seeded with aquifer material from a PCE-contaminated groundwater site in Victoria, Texas, where dehalogenation was occurring. The main microorganisms that resulted in this culture were dehalogenators, which completely transformed PCE to ETH, and hydrogenutilizing methanogens. Little acetoclastic activity was observed. The reactor was maintained at $28( \pm 2)^{\circ} \mathrm{C}$, and remained anaerobic as indicated by absence of color from $1 \mathrm{mg} / \mathrm{l}$ resazurin added in the feed. A continuous anaerobic feed consisting of $1.7 \mathrm{mM}$ sodium benzoate, $20 \mathrm{mg} / \mathrm{l}$ yeast 
extract, $0.98 \mathrm{mM}$ PCE (near saturation) and trace nutrients in basal medium was syringe pumped at $100 \mathrm{ml} / \mathrm{d}$, resulting in a 36-day detention time. Every 2 days, $200 \mathrm{ml}$ liquid was removed to bring the reactor back to 3.61 and for use as the seed culture in batch studies. The basal medium contained the following constituents per liter of Milli-Q water: $0.5 \mathrm{~g}$ of $\mathrm{K}_{2} \mathrm{HPO}_{4}, 1.5 \mathrm{~g}$ of $\mathrm{Na}_{2} \mathrm{CO}_{3}, 20 \mathrm{ml}$ of minerals solution $\left(40 \mathrm{~g} \mathrm{NaCl}, 50 \mathrm{~g} \mathrm{NH}_{4} \mathrm{Cl}, 5 \mathrm{~g} \mathrm{KCl}, 5 \mathrm{~g} \mathrm{KH}_{2} \mathrm{PO}_{4}, 5 \mathrm{~g}\right.$ $\mathrm{MgCl}_{2} \hat{\mathrm{u}} 6 \mathrm{H}_{2} \mathrm{O}, 2 \mathrm{~g} \mathrm{CaCl}_{2} \hat{\mathrm{u}} 2 \mathrm{H}_{2} \mathrm{O}$ per liter), $5 \mathrm{ml}$ of trace metal solution $\left(1 \mathrm{~g} \mathrm{FeCl}_{2} \hat{\mathrm{u}} 4 \mathrm{H}_{2} \mathrm{O}, 1 \mathrm{~g}\right.$ $\mathrm{MnCl}_{2} \hat{\mathrm{u}} 4 \mathrm{H}_{2} \mathrm{O}, 0.2 \mathrm{~g} \mathrm{CoCl}_{2} \hat{\mathrm{u}} 6 \mathrm{H}_{2} \mathrm{O}, 0.12 \mathrm{~g} \mathrm{H}_{3} \mathrm{BO}_{3}, 0.02 \mathrm{~g} \mathrm{ZnCl}_{2}, 0.02 \mathrm{~g} \mathrm{CuCl}_{2} \hat{\mathrm{u}} 2 \mathrm{H}_{2} \mathrm{O}, 0.02 \mathrm{~g}$ $\mathrm{NiCl}_{2} \hat{\mathrm{u}} 6 \mathrm{H}_{2} \mathrm{O}, 0.02 \mathrm{~g} \mathrm{Na}_{2} \mathrm{MoO}_{4} \hat{\mathrm{u}} 2 \mathrm{H}_{2} \mathrm{O}, 0.02 \mathrm{~g} \mathrm{Na}_{2} \mathrm{SeO}_{4}, 0.02 \mathrm{~g} \mathrm{Na}_{2} \mathrm{WO}_{4} \hat{\mathrm{u}} 2 \mathrm{H}_{2} \mathrm{O}, 0.04 \mathrm{~g}$ $\mathrm{Al}_{2}\left(\mathrm{SO}_{4}\right)_{3} \hat{\mathrm{u}} 18 \mathrm{H}_{2} \mathrm{O}, 10 \mathrm{ml} 1 \mathrm{~N} \mathrm{HCl}$ per liter$), 1 \mathrm{ml}$ of filter-sterilized vitamin stock solution $(0.02$ $\mathrm{g}$ biotin, $0.02 \mathrm{~g}$ folic acid, $0.1 \mathrm{~g}$ pyridoxine, $0.05 \mathrm{~g}$ riboflavin, $0.05 \mathrm{~g}$ thiamine, $0.05 \mathrm{~g}$ nicotinic acid, $0.05 \mathrm{~g}$ pantothenic acid, $0.05 \mathrm{~g}$ p-aminobenzoic acid (PABA), $0.05 \mathrm{~g}$ cyanocobalamine, and $0.05 \mathrm{~g}$ thioctic acid per liter), and $5 \mathrm{mg} \mathrm{Na} \mathrm{N}_{2} \mathrm{~S}$ as a sulfur source and reductant.

Batch experiments. Batch studies were conducted using $160 \mathrm{ml}$ serum bottles, with $60 \mathrm{ml}$ headspace filled with a gas mixture $\left(80 \% \mathrm{~N}_{2}, 20 \% \mathrm{CO}_{2}\right)$ and $100 \mathrm{ml}$ liquid volume. Basal medium (containing $20 \mathrm{mg} / \mathrm{l}$ yeast extract) was anaerobically (using gas purging) and aseptically delivered to each bottle. The source cultures were inoculated with syringes. In one experiment to determine the threshold hydrogen concentration for methanogenesis, $10 \mathrm{ml}$ of digested sludge was added to each bottle. Substrates (acetate, benzoate, butyrate, formate, methanol and phenol) were added in an amount equivalent to $30 \mu \mathrm{mol}$ of benzoate (900 micro electron equivalents). No chlorinated ethenes were added. In another experiment to determine the threshold hydrogen concentration for dehalogenation, $10 \mathrm{ml}$ of the PCE-dehalogenating culture from the CSTR, 8 $\mu \mathrm{mol} \mathrm{cDCE}$, and either $30 \mu \mathrm{mol}$ of benzoate or $410 \mu \mathrm{mol}$ of hydrogen were added to each bottle. Control bottles without benzoate and hydrogen were included. In comparative studies with various substrates or electron donors, $50 \mathrm{ml}$ of the dehalogenating source culture was used. Electron donors were added as single doses at the start of the experiment; $5 \mu$ mol cDCE was added initially, and then supplemented repeatedly whenever it became depleted.

To maintain anaerobic conditions, rubber stoppers and aluminum crimp caps were used to seal the bottles. Adsorption of chlorinated compounds on the rubber stoppers was minimal after the first few days so that good mass balances could be maintained throughout the studies. All the 
bottles were continuously mixed at a rate of $100 \mathrm{rpm}$ on a shaker table (Lab-Line Instruments, Inc., Melrose Park, IL). Hydrogen concentration was tracked over time to ensure that it had stabilized at some steady-state concentrations. Duplicates were used in each experiment, and each experiment was repeated at least twice to ensure reproducibility.

Analytical methods. Measurement of PCE, TCE, cDCE, VC, ETH, $\mathrm{CH}_{4}$ and $\mathrm{H}_{2}$ were performed by gas chromatography (GC), using $250 \mu \mathrm{l}$ headspace samples. Compounds were identified by comparison of their retention times with that of external standards. Total amount of gaseous compounds and the concentration of $\mathrm{H}_{2}$ in liquid were calculated by using Henry's law constants published by Gossett (1973) and verified in our laboratory. PCE, TCE, cDCE and VC were determined with a Fractovap 2900 series GC (Carlo Erba Strumentazione, Milan, Italy) equipped with a model PI-52-02A photoionization detector (PID) (10.2 eV lamp; HNU Systems, Inc., Newton, MA), operated isothermally at $40^{\circ} \mathrm{C}$. ETH and $\mathrm{CH}_{4}$ were measured with a model 5730A GC (Hewlett Packard, Palo Alto, CA) equipped with a flame ionization detector (FID) operated isothermally at $90^{\circ} \mathrm{C} . \mathrm{H}_{2}$ was analyzed with a reduction gas detector (RGD)(Trace Analytical, Inc., Menlo Park, CA), having a detection limit just below 0.1 Pa (corresponding to $0.8 \mathrm{nM}$ liquid concentration), which was measured by comparing the response of blanks with standards. All hydrogen concentrations reported thereafter refer to the liquid phase concentration. Benzoate and acetate analyses were performed with a series 4000i ion chromatography (IC) (Dionex, Sunnyvale, CA) equipped with a conductivity detector, a Dionex IonPac AS4A column (4 x 250 $\mathrm{mm})$ and a AG4A guard column $(4 \times 50 \mathrm{~mm})$, operated with sodium tetraborate $(5 \mathrm{mM}, \mathrm{pH}=$ 9.3) as eluant.

\section{Results}

\section{Threshold hydrogen concentration in batch bottles in the absence and presence of cDCE.}

The hydrogen threshold concentration for the process of methanogenesis alone was investigated first with batch studies using digested sludge as seed. Various substrates including acetate, benzoate, butyrate, formate, methanol and phenol were added initially. Except for phenol, the substrates were consumed within two weeks. About two weeks were required to adapt to phenol, and its fermentation was complete within another two weeks. The eventual hydrogen threshold 
concentrations reached were all in the range of 10 to $13 \mathrm{nM}(11.5 \pm 1.6 \mathrm{nM})$. This is just above reported value of 7 to $10 \mathrm{nM}$ for methanogenesis (Lovley and Goodwin, 1988).

The culture from the PCE-dehalogenating CSTR was then used to determine the threshold hydrogen concentration in the absence and presence of cDCE. Benzoate and hydrogen were used as electron donors in this study. For each donor, two bottles had no cDCE added to represent the process of methanogenesis alone, and another two had CDCE added for methanogenesis in combination with dehalogenation.

Without cDCE added, the hydrogen concentration reached about $120 \mathrm{nM}$ during active benzoate fermentation. This initial high hydrogen concentration was partially a result of fermentation of yeast extract which was added as a necessary nutrient for dehalogenation. Three weeks later when benzoate was depleted, hydrogen decreased to $11 \mathrm{nM}$ and remained at that level, even after several months of incubation. Biphasic methanogenesis occurred. Methanogenesis during the first three weeks coincided with the higher hydrogen level, this is believed to be the result of hydrogen-utilizing methanogenesis. Methanogenesis after the hydrogen level dropped to $11 \mathrm{nM}$ is believed the result of acetate-utilizing methanogenesis as acetate then decreased as well. These results are consistent with the control study.

In comparison, hydrogen levels in the bottles to which cDCE was added were different. Hydrogen concentration reached about $180 \mathrm{nM}$ during benzoate fermentation, but decreased to and remained at about $2 \mathrm{nM}$ four weeks later, lower than in the absence of cDCE. Methane production ceased when the hydrogen level decreased. Little acetate was used. This is consistent with the absence of acetoclastic activity observed in the source culture fed PCE (shown later). Since acetoclastic activity eventually resulted in the absence of CDCE, it appears that chloroethenes might be responsible for the inhibition of acetate-utilizing methanogenesis in the cDCE fed batch cultures. There was much less apparent inhibition of hydrogen-associated methanogenesis at the levels of cDCE used.

Dehalogenation of cDCE and VC was detectable at the $2 \mathrm{nM}$ hydrogen level. Following the disappearance of the chlorinated ethenes, the hydrogen concentration increased to a similar level 
of about $11 \mathrm{nM}$ as in the absence of cDCE. But a subsequent respiking with cDCE then caused the hydrogen level to return to about $2 \mathrm{nM}$ (data not shown), confirming that this lower level of hydrogen is related to the process of dehalogenation. With benzoate as electron donor, a mass balance (considering the reducing equivalents of $15 \mu \mathrm{mol}$ as $\mathrm{H}_{2}$ for dehalogenation contributed by the $2 \mathrm{mg}$ yeast extract added, as determined in separate studies) indicates that about $91 \%$ and $9 \%$ of the assumed hydrogen intermediate product was used for the processes of methanogenesis and dehalogenation, respectively. However, dehalogenation became the main hydrogen consumer after the hydrogen concentration was reduced below $11 \mathrm{nM}$.

When hydrogen was added as the electron donor, a similar steady-state hydrogen concentration was observed for $\mathrm{cDCE}$ dehalogenation and methanogenesis . But unlike with benzoate, a sharp drop in the hydrogen level initially was primarily the result of homoacetogenesis (88\%), which was indicated by a significant rise in acetate concentration, rather than methanogenesis $(8 \%)$ and dehalogenation (4\%). However, dehalogenation was again the main hydrogen consumer when the hydrogen level was reduced below $11 \mathrm{nM}$. Similar threshold hydrogen concentrations were obtained with other substrates such as acetate and yeast extract alone. The statistical average values for all substrates are $10.9 \pm 3.3 \mathrm{nM}(\mathrm{n}=40)$ and $2.2 \pm 0.9 \mathrm{nM}(\mathrm{n}=32)$ in the absence and presence of cDCE, respectively.

CSTR evaluation. The PCE dehalogenating CSTR was operated continuously for over two years prior to this study. In this reactor, $980 \mu \mathrm{M}$ PCE was dehalogenated almost completely to ETH, and the liquid concentrations of TCE, cDCE and VC intermediates inferred from headspace analysis were typically below $1 \mu \mathrm{M}$. The hydrogen concentration in the CSTR, also inferred from headspace analysis, maintained itself at $2.6 \pm 0.7 \mathrm{nM}$, which is just slightly above the threshold concentration for dehalogenation found in the batch studies.

Table 2 contains a mass balance summary for the CSTR over a typical 2-day cycle. Assuming benzoate undergoes normal fermentation as follows:

$$
\mathrm{C}_{6} \mathrm{H}_{5} \mathrm{COO}^{-}+6 \mathrm{H}_{2} \mathrm{O}=3 \mathrm{CH}_{3} \mathrm{COO}^{-}+\mathrm{CO}_{2}+2 \mathrm{H}^{+}+3 \mathrm{H}_{2}
$$

three moles each of acetate and hydrogen would be formed from each mole of benzoate. On that basis, the $2.6 \mathrm{~mol}$ of acetate production found from $1.0 \mathrm{~mol}$ of benzoate consumption in the 
reactor indicates that only a small amount of the acetate formed was used in methanogenesis in the reactor. Hydrogen utilization in contrast was essentially complete, and most of the methane production and PCE reduction appear associated with this. Ignoring the smaller contributions of acetate and yeast extract to methane or ethene production, it appears that the hydrogen produced had been used about $58 \%$ for methane production and $42 \%$ for dehalogenation.

Subsequently, the benzoate concentration in the feed to the CSTR was reduced $25 \%$ to $1.28 \mathrm{mM}$ while the PCE concentration was maintained at $0.98 \mathrm{mM}$. No significant reduction in PCE dehalogenation occurred, except for a slight increase in VC concentration from $1 \mu \mathrm{M}$ to between 5 and $10 \mu \mathrm{M}$. Here, the fraction of hydrogen intermediate used for dehalogenation was increased to well over one-half of the available hydrogen.

Two puzzles are associated with the CSTR results. One is the apparent production of methane from hydrogen, even though the liquid hydrogen concentration (based upon head space analysis) remained below the $10 \mathrm{nM}$ threshold required for its conversion to methane. The second is the apparent lack of production of methane from acetate, even though the concentrations of chlorinated ethenes $(<1 \mu \mathrm{M})$ were well below likely inhibitory levels. One hypothesis for these occurrences is mass-transfer limitations, which could result in localized high concentrations hydrogen and chlorinated ethenes before the concentrated feed solution entering the reactor became completely mixed with the CSTR liquid contents. Also, ethene at the level found in the CSTR headspace (0.5\%) has been reported to be inhibitory to methanogenesis (Schink, 1985), although the apparent selective inhibition of acetoclastic methanogenesis only, as suggested here, has not been reported.

\section{Comparison between benzoate and propionate as electron donor for cDCE dehalogenation.}

The study of hydrogen threshold concentration showed that the dehalogenators can use hydrogen when at a lower concentration than the competitive methanogens and homoacetogens. Therefore, a slowly-degrading substrate which produces hydrogen slowly is expected to favor dehalogenation over methanogenesis and homoacetogenesis (Fennell et al., 1997). Propionate was selected for this purpose for two reasons. First, propionate was not a major intermediate in the CSTR, and so the propionate-using population was small, thus propionate utilization was 
expected to be very slow. Also, from an energetic view point, propionate conversion is endergonic at high hydrogen concentration (Fennell et al., 1997). The upper hydrogen concentration at which propionate-degrading bacteria can still obtain energy is $70 \mathrm{nM}$ under the experimental conditions. In contrast, benzoate can result in a hydrogen concentration about 10 times higher.

As expected, significantly different results were obtained with the two selected substrates. Within two and a half months, more than three times the amount of ethene was produced in the propionate-fed bottles as in the benzoate-fed ones, while the amount of methane produced from benzoate was three times that from propionate. In benzoate-fed bottles, after an initial burst, the hydrogen level dropped rapidly to and was maintained thereafter at about $2 \mathrm{nM}$. The initial hydrogen burst corresponded with the rapid fermentation of benzoate and yeast extract which were completed within three weeks. Little hydrogen production was available after that for dehalogenation. In contrast, propionate was used slowly over about three months. As a result, a much higher hydrogen level (but below $11 \mathrm{nM}$ most of the time) and dehalogenation rate were maintained for a longer period.

Oleate and tetrabutyl orthosilicate. Oleate is a typical anaerobically-biodegradable long-chain fatty acid that is converted via the $\beta$-oxidation pathway into 9 moles of acetic acid and 15 moles of hydrogen (Jeris and McCarty, 1965). At millimolar concentrations oleate inhibits acetogens and methanogens, but inhibition can be reduced if calcium ion is added to form a calcium oleate precipitate(McCarty, 1964). Such a precipitate may effect a slow dissolution of oleate and a resulting slow production of hydrogen. However, oleate was here found to be toxic to the dehalogenating microorganisms as well. About 50 days were required for dehalogenation to begin, but only about 20 days for methanogenesis. The calcium present $(0.14 \mathrm{mM})$ was insufficient to reduce inhibition adequately. As a consequence of the greater impact on dehalogenators, the utilization efficiency of oleate for dehalogenation was the lowest, only $2 \%$.

A further experiment was conducted with oleate by varying the amount of calcium amended to investigate the function of calcium to detoxify oleate. This batch study was prepared similarly as above except $8.2 \mu \mathrm{mol}$ of oleate was used as substrate $(0.137 \mathrm{mM})$, and $0.14 \mathrm{mM}, 0.82 \mathrm{mM}$ and 
$2.87 \mathrm{mM}$ of calcium chloride were added respectively. It was found that sufficient calcium indeed could reduce the toxicity of oleate. With $0.82 \mathrm{mM}$ and $2.87 \mathrm{mM}$ of calcium, dehalogenation started much earlier and much more ethene was produced than with $0.14 \mathrm{mM}$ of calcium. Mass balance indicated that the utilization efficiency of oleate with $0.14 \mathrm{mM}, 0.82 \mathrm{mM}$ and $2.87 \mathrm{mM}$ of calcium for dehalogenation is $0.5 \%, 10.8 \%$ and $9.3 \%$ respectively. This suggested that sufficient calcium is necessary to detoxify oleate, but too much would not have a better effect.

Alkoxysilanes such as TBOS slowly hydrolyze to 1-butanol (30), which was biodegraded to yield hydrogen to support TCE dehalogenation (Vancheeswaran, et al., 1998). TBOS supported dehalogenation in this study as well, yielding $36 \mu$ mol ethene within 4 months after an initial 20 days lag time. However, methanogenesis started immediately. More electrons may have been imparted to dehalogenation had microorganisms pre-adapted to TBOS been used. The mass balance for TBOS was about $20 \%$ deficient. The utilization efficiency for dehalogenation was $8.9 \%$, not considering the missing portion.

Biomass. Biomass is produced as a result of substrate utilization. The normal decay of biomass follows a first-order rate process that may provide electrons useful to dehalogenating organisms. Biomass can be produced in aquifers such as through the introduction of carbohydrates. Biomass is particulate and likely to remain in place where grown, and thus has good potential for a bioremediation barrier wall. The purpose of this study was to compare biomass as a possible substrate for dehalogenation with other potential electron donors. Mixed bacterial biomass was grown separately in nutrient broth, harvested, washed, and then added to batch bottles along with cDCE.

Both methanogenesis and dehalogenation started immediately with the biomass substrate. Methane was produced most rapidly over the first 20 days, and was probably associated with rapid hydrogen evolution from the more easily degradable portions of biomass. After that, methanogenesis slowed. The rate of dehalogenation also decreased with time, as would be expected from the gradual destruction of biomass. However, over the 4 month period, more ethene was produced than methane. Considering only the utilized biomass (that transformed to 
ethene, methane and acetate), $20 \%$ of the biomass substrate was used in dehalogenation for the $25 \mathrm{mg}$ biomass case. This mass balance here is incomplete by about $40 \%$, an amount that perhaps represents the portion of the biomass that did not degrade within the study period. About $20 \%$ of biomass is known to be especially difficult to biodegrade.

With an increase to $50 \mathrm{mg}$ biomass, slightly more ethene was produced, but the increase in methane was greater. As a result, only $14 \%$ of the biomass consumed was channeled to dehalogenation. This could be due to the frequent cDCE limitation during the study, which was observed when cDCE was supplemented each time, suggesting that a higher efficiency could be attained when cDCE is not limited. The frequent cDCE limitation during the study, as observed when cDCE was supplemented each time and as suggested by the higher dehalogenation rate from day 45 to day 75 than that from day 0 to day 20 , suggested that the increase of substrate amount would not improve substrate utilization efficiency as much.

\section{Discussion}

The study of hydrogen threshold concentrations indicates that the dehalogenators present in the studied mixed culture were able to use hydrogen when at a lower concentration than can be used by the competitive homoacetogens and methanogens. The hydrogen threshold concentration observed in the batch reactors was $2.2 \pm 0.9 \mathrm{nM}$ for dehalogenators, and $10.9 \pm 3.3 \mathrm{nM}$ for methanogens. The small difference in these values, regardless of the electron donors used, suggests that the hydrogen threshold concentration is independent of the electron donor used and the processes of hydrogen production.

Theoretically the threshold concentration of hydrogen for a given reaction in which it is the electron donor is influenced by the energy yield available from its oxidation; an inverse correlation should exist between the free energy of the reaction and the steady-state hydrogen concentration (Cord-Ruwisch, et al., 1988). This partially explains the lower hydrogen threshold concentration for dehalogenators as the free energy from the dehalogenation reaction is much more than that from the methanogenic and homoacetogenic processes. The free energy available to each group of microorganisms at its apparent hydrogen threshold is listed in Table 3. 
Obviously, methanogens and homoacetogens are very efficient in energy conservation because at their threshold concentration the energy available is very close to the reported lowest net energy required by microorganisms for growth. Dehalogenators, however, have more energy available to them from hydrogen oxidation at their threshold concentration. This may mean that they are not as efficient at capturing the energy available from hydrogen oxidation as the other organisms.

In spite of the fact that the hydrogen producing processes have no apparent effect on the hydrogen threshold, the available hydrogen level is a determining factor for the activity of the different competing microorganisms. With benzoate as the primary electron donor in the batch experiments, the resulting initial hydrogen level was much higher than the threshold concentrations for either methanogens or dehalogenators, but lower than that required thermodynamically for homoacetogenesis. Thus methanogens and dehalogenators were the main consumers of hydrogen, with methanogenesis dominating. In contrast, with hydrogen as the primary electron donor, homoacetogens became the dominant group in hydrogen utilization with their advantageous kinetic properties.

Comparative studies with benzoate and propionate further confirm the importance of the hydrogen level. When benzoate was used as substrate, its rapid fermentation and thereby rapid hydrogen production and a higher than methanogenic hydrogen threshold concentration resulted over the first few weeks. Most of this hydrogen therefore was consumed by the methanogens. Subsequently, a lower hydrogen level and dehalogenation rate resulted. In contrast, the small propionate-utilizing population and thermodynamic regulation of propionate fermentation caused an initially slower release of hydrogen, but one that was maintained much longer. The net result was a higher long-term hydrogen production rate that produced a persistent hydrogen level just below the threshold for methanogens. This not only limited methanogenesis, but also resulted in a higher rate of dehalogenation. This result is consistent with the short-term studies by Fennel et al. (1997).

The manner in which the electron donor is delivered to the microorganisms is also a major factor affecting the outcome of competition for hydrogen as suggested by comparison results between the CSTR and the batch reactors. In the batch study with benzoate, its rapid fermentation caused 
hydrogen to accumulate above the threshold concentration for methanogens. This gave the methanogens the opportunity to obtain a far greater share of available reducing equivalents than the dehalogenators, which obtained only $9 \%$. However, with continuous benzoate feed to a CSTR, hydrogen remained at a low steady-state concentration near the dehalogenation threshold of about $2 \mathrm{nM}$. Here, dehalogenation of PCE to ETH was complete, a process which consumed over one-half of the potentially available hydrogen. Just considering the conversion of cDCE to ETH, about one-quarter of the available hydrogen was consumed for this conversion compared with $9 \%$ in the batch study.

These results suggest approaches that may be used to impart a competitive advantage to dehalogenating microorganisms in bioremediation. When methanogens are the main competitors for hydrogen, efficient use of hydrogen for dehalogenation can be obtained by strategies that maintain the hydrogen concentration between 2 and $11 \mathrm{nM}$. This might be realized in either of three ways: first, by adjusting the delivery rate of hydrogen precursors, such as benzoate, to the microorganisms in order to achieve an effect similar to that obtained in the CSTR; second, through use of an appropriate hydrogen precursor which is slowly degradable so that it can release hydrogen in a slow manner to maintain the ideal hydrogen concentration as found here with propionate; and third, by use of a hydrogen precursor as the primary electron donor that requires a very low hydrogen partial pressure thermodynamically for the fermentation to occur, perhaps somewhat similar to the case here with propionate.

The efficiency by which different substrates might be used for dehalogenation in competition with methanogenesis was studied with batch cultures. In comparing these values, it must be noted that much higher efficiencies for dehalogenation can be obtained with continuous culture where the hydrogen concentration can more easily be maintained below the threshold of 10-12 $\mathrm{nM}$ for methanogenesis. Under such conditions, the efficiency with benzoate was about $15 \%$ rather than the $4.2 \%$ found here in batch studies. Thus, conditions of addition are important in comparing efficiencies.

In complete anaerobic fermentation of organic materials, a portion of the electrons available is converted either to acetate or hydrogen. Following normal pathways of biodegradation under 
methanogenic or dehalogenation conditions, the portion of electrons converted to hydrogen is about 30 to 33\% (Jeris and McCarty, 1965), which appears to be the dominant electron donor for reductive dehalogenation of $\mathrm{CDCE}$ and VC. The portion is similar to this for carbohydrates, proteins, long-chain fatty acids, and benzoate. With propionate, the portion converted to hydrogen is somewhat higher, about $43 \%$. Thus, 30 to $43 \%$ utilization efficiency for substrate dehalogenation represents the general upper bound for the compounds studied with our culture and with cDCE. In batch culture here, propionate and biomass came closest to the efficiency upper bound. The relatively slow rate of decomposition of each is largely responsible for the higher efficiencies as this in effect simulates the controlled continuous feeding of substrate in continuous culture. In addition, thermodynamic factors help maintain a lower hydrogen concentration with propionate, which also helps increase conversion efficiency.

The above considerations indicate the advantage of propionate as a substrate for dehalogenation. A disadvantage with both propionate and benzoate for in situ biodegradation of chloroethenes is the difficulty of mixing them with the contaminants. The general approach here is a continuous pumping system such as recirculation wells or continuous groundwater extraction, chemical introduction, and then reinjection. An alternative of much interest is a more passive approach using insoluble slow hydrogen release compounds such as organosilicon compounds, of which TBOS is a representative. Such compounds can be placed in a barrier system, and their slow hydrolysis will introduce organic electron donors continuously into contaminated aquifer water as it passes by. If the amount introduced and the hydrolysis rate are carefully controlled to match the mass per unit time of contaminants passing, then a high efficiency of utilization for dehalogenation can be obtained. The costly aspect of this approach is building the reaction wall into which the compounds are introduced. An alternative approach is to use of a series of closely spaced wells where the insoluble compounds can be placed and then replaced as necessary following hydrolysis and utilization.

The use of biomass or a compound such as oleate represent a third alternative that lies somewhere between the above two approaches. Here, an injection and extraction well system might be placed across a contaminated plume. For the biomass approach, a high-biomassyielding compound, such as a carbohydrate, is introduced into the aquifer rapidly with the 
injection well and pulled laterally across the plume by pumping at the extraction well. Fermentation of the carbohydrate results in the production of biomass in a curtain across the plume. Then, slow biomass decomposition results in the slow hydrogen release desired. Oleate offers a similar alternative. The sodium salt is soluble and can be introduced across the plume as with glucose. This would be followed by calcium chloride introduction to cause precipitation as calcium oleate to form a slow release organic curtain across the plume. This might be accomplished by sequential pulsing of sodium oleate and calcium chloride, making use of longitudinal dispersion to mix the calcium and oleate. This is obviously more difficult than carbohydrate introduction, but has its own advantages.

While the relatively high utilization efficiency with biomass is attractive, a disadvantage is in the relatively low biomass yield under anaerobic conditions. The typical electron conversion yield of a carbohydrate into biomass under anaerobic conditions is a maximum of about $28 \%$ (31). Considering that the refractory fraction of biomass is about $20 \%$, and that the hydrogen producing potential of the biodegradable fraction is 30\%, then the upper limit on the amount of carbohydrate electrons that would be available for reductive dehalogenation would be $0.28 \times(1$ $0.2) \times 0.3 \times 100$ or $6.7 \%$. The actual amount used for dehalogenation would likely be less than this. While the overall yield is low, the ease of carbohydrate introduction to produce a curtain of biomass across a plume may be attractive.

This study has examined three different classes of organic substances that might be introduced into an aquifer as electron donors for in situ anaerobic reductive dehalogenation of chloroethenes. Each has particular advantages and disadvantages in efficiency of electron use for reductive dehalogenation and method and ease of introduction into an aquifer. Some require a more active approach for bioremediation, while others offer a passive approach. They each differ in chemical cost, but perhaps more important considerations are the capital and operating costs for chemical introduction and for the maintenance of activity for biodegradation over time. However, field studies are too limited at this time to suitably judge the advantages of one chemical over the other or of active approaches versus more passive approaches to bioremediation. More efforts in this direction are needed. 


\section{PROCESS KINETICS}

Investigators: Z C. Haston, Y. Yang, and P. L. McCarty

In anaerobic dechlorination of PCE and CDCE, these CAHs serve as electron acceptors. Because the VC intermediate is more hazardous and has a lower drinking water standard, complete dechlorination of $\mathrm{cDCE}$ and $\mathrm{VC}$ to ethene is needed for effective bioremediation. The effects of hydrogen electron donor and $\mathrm{CAH}$ electron acceptor concentrations have been reported. However, to predict dehalogenation in the field or in a reactor, more information is needed on the growth rates of dechlorinating microorganisms and the kinetic interactions between the acceptors. The objective of this study was to investigate and model growth and substrate utilization kinetics for the cDCE and VC dehalogenators in a mixed PCE-dechlorinating culture. More detailed information is contained in the project publications: Haston, Z. C. (1999), Factors Affecting Growth and Utilization in the Anaerobic Dehalogenation of Chlorinated Ethenes, Ph.D. Dissertation, Stanford University; Haston, Z. C. and McCarty, P. L. (1999), "Chlorinated Ethene Half-Velocity Coefficients $\left(K_{s}\right)$ for Reductive Dehalogenation," Environmental Science and Technology, 33(2), 223-226; and Haston, Z. C., Yang, Y., and McCarty, P. L.(2000), "Organism Growth and Substrate Utilization Kinetics for the Anaerobic Dehalogenation of cis-Dichloroethene and Vinyl Chloride," submitted for publication .

\section{Materials and Methods}

Culture. An anaerobic mixed culture capable of completely dechlorinating PCE to ethene was originally seeded with aquifer material from a PCE-contaminated site in Victoria, TX. This site had been bioremediated under sulfate-reducing conditions through the addition of benzoate (Beeman, et al., 1994). The culture was originally enriched using site groundwater to which was added $60 \mathrm{mg} / \mathrm{L}$ sodium benzoate, $2 \mathrm{mmol}$ hydrogen, and $30 \mu \mathrm{M}$ PCE. Benzoate and hydrogen were used in excess to ensure that complete dechlorination was obtained. Site groundwater was later replaced with a basic mineral medium (Yang and McCarty, 1998) containing $20 \mathrm{mg} / \mathrm{L}$ yeast extract as well as the benzoate, hydrogen, and PCE. With this composition, PCE was essentially the only external electron acceptor present. After several transfers using $10^{-3}$ dilutions, the resulting culture was used for an anaerobic continuously stirred tank reactor (CSTR) that was 
operated at $25^{\circ} \mathrm{C}$ and continuously fed $100 \mathrm{~mL} /$ day basic mineral media containing $0.7 \mathrm{mM}$ PCE, $1.74 \mathrm{mM}$ benzoate, and $20 \mathrm{mg} / \mathrm{L}$ yeast extract, yielding a 36 day detention time. Additionally, $1 \mathrm{mmol}$ of hydrogen was added every 2 days to the headspace of the $4.3 \mathrm{~L} \mathrm{CSTR}$ which had a 3.6 L liquid volume. PCE was dechlorinated to ethene in the reactor, and benzoate was completely consumed producing acetate and methane (Yang and McCarty, 1998). After several months of operation, effluent from this CSTR was used as seed culture for batch kinetic studies. Volatile suspended solids (VSS) in the reactor during these experiments remained at $58 \pm 2 \mathrm{mg} / \mathrm{L}$, and the $\mathrm{pH}$ was $7.1 \pm 0.2$.

Batch studies. Batch studies were conducted at $25^{\circ} \mathrm{C}$ by adding $76 \mathrm{~mL}$ of basic mineral media, $4.4 \mathrm{mg}$ yeast extract, and $13 \mathrm{mg}$ sodium benzoate into $254 \mathrm{~mL}$ bottles capped with Mininert valves (Alltech, Deerfield, Ill.) in an anaerobic glove box which was filled with $80 \%$ nitrogen, $10 \%$ carbon dioxide, and $10 \%$ hydrogen. CAHs were then added from stock solutions. Following shaking horizontally in the glove box on a shaker table set at $1000 \mathrm{rpm}$, the bottles were seeded with $144 \mathrm{~mL}$ of fresh culture from the CSTR, resulting in a VSS concentration of 38 $\mathrm{mg} / \mathrm{L}$. Bottles with different initial concentrations of each chlorinated ethene were operated simultaneously on the shaker table. Initial dehalogenation rates were measured, generally over a period of less than an hour, before subsequent dehalogenation products rose to concentrations that otherwise might have affected the rates. Control bottles showed no significant losses of the CAHs during this time. Dechlorination progress and rates were measured by headspace analysis with initial and final aqueous samples also being taken for comparison of aqueous to headspace chlorinated ethene concentrations. Headspace samples were also taken for hydrogen analyses.

The ratio of headspace to aqueous $\mathrm{CAH}$ concentrations at the start and finish of these experiments is summarized in Table 4. The ratios compare well to their reported dimensionless Henry's constants, and no significant change was observed in this ratio as the concentration decreased during these experiments, indicating good mass transfer between gas and liquid phases for these compounds in these vigorously shaken bottles. During all batch experiments, headspace hydrogen concentrations ranged between 6 and $7 \mathrm{kPa}$. This would result in equilibrium liquid concentrations which are 2 or 3 orders of magnitude greater than the $K_{S}$ values for hydrogen reported by others (Ballapragada, et al., 1997; Smatlak et al., 1996) and so was not 
expected to be rate limiting. To further check for a dechlorination rate dependence on hydrogen concentrations, $6 \mu \mathrm{M}$ PCE was added to batch bottles with headspace hydrogen concentrations ranging from 0.6 to $15 \mathrm{kPa}$. No significant change in dechlorination rate was observed through this range of hydrogen concentrations. Additionally, initial dechlorination rates were not observed to change by increasing yeast extract concentrations up to $200 \mathrm{mg} / \mathrm{L}$ nor with benzoate concentrations up to $1.7 \mathrm{mM}$. With good mass transfer and the electron donors in excess, true intrinsic $K_{S}$ values for the chlorinated compounds could thus be determined using head space measurements.

CAH utilization rate. Batch experiments were conducted at $25^{\circ} \mathrm{C}$ by adding into $56 \mathrm{~mL}$ bottles $30 \mathrm{~mL}$ of mineral media containing $60 \mathrm{mg} / \mathrm{L}$ sodium benzoate and $20 \mathrm{mg} / \mathrm{L}$ yeast extract. These were capped with Mininert valves (Alltech, Deerfield, IL) in an anaerobic glove box filled with $80 \%$ nitrogen, $10 \%$ carbon dioxide, and $10 \%$ hydrogen. CAHs were added from stock solutions. After 10 min of shaking horizontally in the glove box on a shaker table set at $1000 \mathrm{rpm}$, the bottles were seeded by syringe with $10 \mathrm{~mL}$ of culture from the CSTR. Bottles containing different initial concentrations of the chlorinated ethenes were operated simultaneously on the shaker table, and initial dehalogenation rates were measured by headspace analyses. Control bottles showed no significant losses of the CAHs during this time. Final hydrogen headspace concentrations were above $4 \%$ in all bottles so that electron-donor concentration would not limit the reaction rate.

Growth rate. The growth rate of the culture was measured in $160 \mathrm{~mL}$ bottles containing various concentrations of initial biomass along with $100 \mathrm{~mL}$ of basal mineral media, $60 \mathrm{mg} / \mathrm{L}$ sodium benzoate, and $20 \mathrm{mg} / \mathrm{L}$ yeast extract. The bottles were capped with gray rubber stoppers (Bellco Glass Inc., Vineland, NJ) and aluminum crimp caps in the above $25^{\circ} \mathrm{C}$ anaerobic glove box, and CAHs were added by syringe. Bottles were shaken by hand twice daily.

In VC growth rate studies, the CSTR culture was diluted to yield concentrations in different bottles of $6.2,1.6,0.78,0.39,0.19,0.097$, and $0.081 \mathrm{mg} / \mathrm{L} \mathrm{VSS}$, and $5.7 \mu$ moles of VC was added to the bottles. An additional control bottle containing $0.097 \mathrm{mg} / \mathrm{L} \mathrm{VSS}$ was established, but no VC was added to this bottle. For cDCE growth rate evaluation, commercial cDCE 
(Aldrich, Milwaukee, WI) was added to give an initial aqueous concentration of $60 \mu \mathrm{M}$ in different bottles initially containing $3.5,0.87,0.22,0.054,0.014$, or $0.0034 \mathrm{mg} / \mathrm{L}$ VSS. In both these $\mathrm{VC}$ and $\mathrm{CDCE}$ growth studies, headspace hydrogen concentrations at the completion of dechlorination remained above $0.12 \%$, and autoclaved controls had less than a $5 \%$ loss of the added $\mathrm{CAH}$ during the experiment.

To investigate the influence of commercial cDCE concentrations on the growth rate, different concentrations were added to the $160 \mathrm{~mL}$ batch bottles along with $0.076 \mathrm{mg} / \mathrm{L}$ VSS of the mixed culture. Autoclaved controls were included for mechanical losses, and two live controls were added in which no $\mathrm{CDCE}$ was added. Headspace hydrogen concentrations remained above $0.15 \%$ at the completion of dechlorination, and autoclaved controls had less than a $4 \%$ loss of cDCE during the experiment.

The influence of commercial cDCE on methane production was evaluated in smaller $40 \mathrm{~mL}$ bottles, but containing the same mineral, benzoate, hydrogen, and yeast extract concentrations as above together $4.5 \mathrm{mg} / \mathrm{L}$ VSS of the mixed culture in $25 \mathrm{~mL}$ media. Various concentrations of commercial cDCE were added prior to incubation.

Biogenic cDCE studies. Possible differences reported by S. Zinder (personal communication) between biologically generated cDCE and commercial CDCE were also evaluated. Biogenic cDCE was generated by adding PCE (Aldrich, Milwaukee, WI) periodically to a culture of strain MS-1, which is known to dechlorinate PCE to cDCE (Sharma and McCarty, 1996). MS-1 was grown on acetate and yeast extract in a $160 \mathrm{~mL}$ bottle containing $100 \mathrm{~mL}$ of a basal medium (Sharma and McCarty, 1996). After about $2.2 \mathrm{mM} \mathrm{cDCE}$ had been produced, $4.5 \mathrm{~mL}$ of solution was transferred by syringe into $60 \mathrm{~mL}$ serum bottles containing $30 \mathrm{~mL}$ of headspace $\left(80 \% \mathrm{~N}_{2}\right.$, $20 \% \mathrm{CO}_{2}$ ), $25 \mathrm{~mL}$ basal media, $320 \mathrm{mg} / \mathrm{L}$ sodium benzoate, and $20 \mathrm{mg} / \mathrm{L}$ yeast extract. Some of the biogenic solution was sparged free of cDCE, and $4.5 \mathrm{~mL}$ was added to parallel bottles, followed by the addition of commercial $\mathrm{CDCE}$ at equivalent concentrations to that in the biogenic bottles. The bottles were capped with rubber stoppers and aluminum crimp caps and incubated on a shaker table (Lab-Line Instruments, Inc., Melrose Park, IL) at 100 rpm. 
The influence of increasing concentrations of biogenic cDCE on its dehalogenation was also examined. Here, a $35 \mathrm{~mL}$ liquid volume was used containing basal media, $40 \%$ inoculation of reactor culture, $320 \mathrm{mg} / \mathrm{L}$ sodium benzoate, $20 \mathrm{mg} / \mathrm{L}$ yeast extract, and various concentrations of the biogenic cDCE. Various amounts of biogenic cDCE solution were sparged free of cDCE, and an amount was added to the different volumes so that the total amount of biogenic solution present was the same in all bottles.

Analytical Methods. $0.25 \mathrm{~mL}$ headspace samples were used for the measurement of hydrogen, ethene, ethane, methane, PCE, TCE, cDCE, and VC. Chlorinated ethenes were measured with a Fractovap 2900 series gas chromatograph (Carlo Erba Strumentazione, Milan, Italy) equipped with a $10.2 \mathrm{eV}$ photo ionization detector (PID) which was operated isothermally at $60^{\circ} \mathrm{C}$ for PCE and TCE, or $40^{\circ} \mathrm{C}$ for $\mathrm{cDCE}$ and $\mathrm{VC}$ rate experiments. Methane, ethene, and ethane were analyzed with a gas chromatograph (Hewlett-Packard model 5730A, Palo Alto, CA) operated isothermally at $90^{\circ} \mathrm{C}$ with a packed $60 / 80$ Carbosieve $\mathrm{G}$ column ( 5 ft. by 0.125 in.; Supelco, Bellefonte, Pa.) and a flame ionization detector (FID). Hydrogen concentrations were measured with a reduction gas detector (RGD2; Trace Analytical, Menlo Park, CA).

$200 \mu \mathrm{L}$ aqueous samples were analyzed for chlorinated ethene concentrations using a Tekmar Model 4000 Dynamic Headspace Concentrator with a Model ALS Automatic Laboratory Sampler to purge-and-trap the CAHs followed by separation with an HP 5890 Series II gas chromatograph and quantification with a Tracor 700A HALL electrolytic conductivity detector. The samples were purged at $30^{\circ} \mathrm{C}$ for $10 \mathrm{~min}$, and desorbed for $2.5 \mathrm{~min}$ at $110^{\circ} \mathrm{C}$ followed by baking at $150^{\circ} \mathrm{C}$ for $2 \mathrm{~min}$. The gas chromatograph was set at $45^{\circ} \mathrm{C}$ for $10 \mathrm{~min}$, ramped at $70^{\circ} / \mathrm{min}$ to $150^{\circ} \mathrm{C}$, and held for $4.3 \mathrm{~min}$. In all cases, identification and quantification was by comparison with external standards.

Chemicals and gases. Chemicals for the media along with the chlorinated compounds PCE, TCE, and cDCE in high purity were obtained from Sigma and Aldrich (Milwaukee, Wis.). VC (>99.5\% pure) was obtained from Fluka (Milwaukee, Wis.). Yeast extract was obtained from Difco Laboratories. Standards for hydrogen, methane, ethene, and ethane in nitrogen were obtained from Alltech (Deerfield, Ill). 
Biomass determination. With the mixed culture, biomass in the bottles was measured with each experiment as volatile suspended solids (VSS) according to standard methods (Eaton, et al., 1995) using a GF/F filter and triplicate controls.

\section{Results}

Data analysis. The rate of dehalogenation of a given CAH may be influenced by a number of factors, including the concentrations of both the electron donor and acceptor (CAH), potential toxicity of the $\mathrm{CAH}$ itself, and competitive inhibition. However, in all experiments reported herein, the concentrations of CAHs were kept below toxic levels (19), and the donor, hydrogen, was kept in excess. Potential product competitive inhibition was avoided by measuring initial dehalogenation rates before product concentration became an issue. Thus experimental conditions reduced the predicted dehalogenation rate to the simple form:

$$
-\frac{d S}{d t}=\frac{k X S}{S+K_{S}}
$$

where $S$ is the CAH concentration, $K_{S}$ is its half-velocity coefficient, $k$ is the maximum CAH dechlorination rate per unit biomass, and $X$ is the biomass concentration. Biomass concentrations remained constant during these short experiments. Initial dehalogenation rates $(-d S / d t)$ were measured over a range of chlorinated ethene concentrations $(S)$ for each of the CAHs. A straight-line fit through the initial points was used to find the dechlorination rate, with the standard error of the slope being used to find $95 \%$ confidence intervals. The first measured $\mathrm{CAH}$ concentration was used as the initial concentration for this rate. The values $k X$ and $K_{S}$ were then calculated for each chlorinated ethene by minimizing the sum of the squares of the difference between the measured initial rate for a given concentration and that predicted by Equation 1. Properties of the non-linear least squares estimates of $k X$ and $K_{S}$ were analyzed by standard procedures (20), and are reported as $95 \%$ confidence intervals. 
Model Development. For modeling organism growth rate and CAH dehalogenation rates, a more inclusive model is required than that given by Equation 1. A number of models have been suggested and used for anaerobic dehalogenation (Bagley, 1998; Corapcioglu and Hossain, 1991; Fennell and Gossett, 1998; Skeen, et al., 1995; Tonnaer, et al., 1997; Wrenn and Rittmann, 1995). Fennell and Gossett (1998)modeled dechlorination in a culture that contains a microorganism that degrades PCE to VC with growth, and then dechlorinates VC cometabolically yielding no biomass. Without a buildup of cDCE in the system, competitive inhibition between cDCE and VC did not need to be included. Tonnaer et al.(1997)incorporated growth in a model for dechlorination in soil columns. Three species were assumed for the dechlorination of PCE to ethene. One species was assumed to grow through PCE and TCE dehalogenation. Such growth included competitive inhibition. Dechlorination of cDCE and VC were assumed each to be carried out by different species, and no competitive inhibition was included between cDCE and VC. Bagley (1998) developed a general growth model for the case where one species was responsible for both PCE and TCE dechlorination, and another species for $\mathrm{CDCE}$ and $\mathrm{VC}$ dehalogenation. Our previous studies have indicated for our culture that dechlorination of PCE to ethene involves two separate species, one that converts PCE and TCE to cDCE, and the other, cDCE and VC to ethene (Haston and McCarty, 1999; Rosner, et al., 1997; Sharma and McCarty, 1996). Ballapragada et al. (Ballapragada et al., 1997) reported the same for their mixed culture.

Incorporating competitive inhibition between $\mathrm{CDCE}$ and $\mathrm{VC}$ with inhibition constants comparable to their respective half-velocity coefficients, and including a minimum threshold value, $S_{H}^{*}$, for the hydrogen electron donor with concentration $S_{H}$ (Fennell et al., 1997), the dechlorination rate of cDCE can be generally expressed by Equation 1 where $S_{i}$ is the aqueous concentration of $\mathrm{cDCE}$ and $S_{j}$ that of $\mathrm{VC}, \hat{q}_{i}$ is the maximum specific dechlorination rate of cDCE per unit of dechlorinating biomass, $X$ is the concentration of dechlorinating biomass, $K_{i}$ is the half-velocity coefficient for cDCE, $K_{j}$ is the competitive inhibition constant for VC on cDCE dechlorination, and $K_{H}$ is the half-velocity coefficient for the electron donor, hydrogen. 


$$
-\frac{d S_{i}}{d t}=\left|\frac{\hat{q}_{i} X S_{i}}{S_{i}+K_{i}\left|1+\frac{S_{j}}{K_{j}}\right|}\right| \frac{S_{H}-S_{H}^{*}}{\left(S_{H}-S_{H}^{*}\right)+K_{H}} \mid
$$

A similar equation can be written for $\mathrm{VC}$ dechlorination, but with interchange in the $i$ and $j$ subscripts of Equation 2.

The rate of dechlorination increases with time due to organism growth. When one species can grow either through $\mathrm{CDCE}$ or $\mathrm{VC}$ dehalogenation, the rate of growth of the biomass can be expressed by Equation 2 where $Y_{i}$ and $Y_{j}$ are the yields of biomass per mass of cDCE and VC dechlorinated, respectively, and $\mathrm{b}$ is the decay rate.

$$
\frac{d X}{d t}=Y_{i}-\frac{d S_{i}}{d t}+Y_{j}\left(-\frac{d S_{j}}{d t}\right)-b X
$$

In a mixed population where the concentration of dechlorinating organisms, $X$, is not known, the specific growth rate, $\mu$ (day ${ }^{-1}$ ), can be derived with respect to the maximum specific growth rates, $\hat{\mu}$. For example, for cDCE dehalogenation, $\hat{\mu}_{\mathrm{i}}$ is the product of the yield, $Y_{i}$, and maximum degradation rate, $\hat{q}_{i}$. The resulting growth rate expression with growth on both electron acceptors is shown in Equation 4.

$$
\mu=\frac{d X / d t}{X}=\left|\frac{\hat{\mu}_{i} S_{i}}{S_{i}+K_{i}\left(1+\frac{S_{j}}{K_{j}}\right)}+\frac{\hat{\mu}_{j} S_{j}}{S_{j}+K_{j}\left(1+\frac{S_{i}}{K_{i}}\right)}\right|_{\mid}^{\lceil}\left|\frac{S_{H}-S_{H}^{*}}{\mid}\right|-b
$$

Additionally, in these studies commercial CDCE was found to be inhibitory to organism growth rate at higher concentrations, an effect that appeared proportional to the amount added. The natural decay rate, $b$, was found insignificant by comparison. This effect was modeled by 
the addition of an inhibition constant, $\Lambda$. Also, in order to examine the maximum growth rates on $\mathrm{CDCE}$ and $\mathrm{VC}$, the electron donor, hydrogen, was kept in excess for all experiments contained herein. These modifications to general Equation 4 resulted in the altered model as used in this study for the case where the electron acceptor concentrations are reaction rate limiting:

$$
\mu=\frac{d X / d t}{X}=\left|\frac{\hat{\mu}_{c D C E} S_{c D C E}}{\left|S_{C D C E}+K_{c D C E}\right| 1+\frac{S_{V C}}{K_{V C}} \mid}+\frac{\hat{\mu}_{V C} S_{V C}}{S_{V C}+K_{V C}\left(1+\frac{S_{C D C E}}{K_{c D C E}}\right)}\right|-\Lambda S_{c D C E}^{o}
$$

Data Analysis. Data from each study was fit by non-linear least squares analyses to Equations 1 and 5 to estimate the model parameters. Properties of the non-linear least squares estimates of reaction coefficients were analyzed by standard procedures (Mendenhall and Sincich, 1992), and are reported here as $95 \%$ confidence intervals.

Determining $\boldsymbol{K}_{\boldsymbol{s}}$ Values. The computed maximum degradation rates $(k X)$ and half-velocity coefficients $\left(K_{S}\right)$, along with their $95 \%$ confidence intervals are summarized in Table 5. Maximum degradation rates depend upon the concentration of dechlorinating organisms, which is some portion of the total biomass measured as volatile suspended solids, and therefore varies widely from culture to culture. For comparison, the maximum dechlorination rates $(k X)$ reported here are higher than in the sediment microcosms of Barrio-Lage et al. (1987; 1986), comparable with the column results of deBruin et al. (1992), and lower than the expanded-bed reactor findings of (Carter and Jewell, 1993). These reports were for different total biomass concentrations, and the proportion of actual dechlorinators in each would no doubt depend upon the feed type and level of enrichment. Similarly, the maximum dechlorination rate per mg of biomass with our mixed culture is 1 to 2 orders of magnitude lower than has been reported for pure cultures or cell extracts (Maymo-Gatell et al., 1997; Rosner et al., 1997; Scholz-Muramatsu et al., 1995; Sharma and McCarty, 1996). It should be noted that although VC is frequently reported by others to be degraded much slower than the other chlorinated ethenes (Vogel et al., 1987)), it was found here to be degraded at about the same rate as CDCE. However, PCE and TCE conversion rates were much higher than that for CDCE and VC as commonly reported. 
Additionally, the conversion rates of the four CAHs in the CSTR $(0.34 \mu \mathrm{mol} / \mathrm{mg} \mathrm{VSS} \cdot \mathrm{d})$ was about the same as the $k_{\text {app }}$ for CDCE and VC, but only about 20 percent of that for PCE and TCE. Thus the CSTR had little additional capacity for cDCE and VC transformation, but much more for PCE and TCE transformation. This is also in accordance with the generally observed rate differences between the more chlorinated and less chlorinated CAHs.

The half-velocity coefficients $\left(K_{S}\right)$ measured here are an order of magnitude lower than BarrioLage et al. $(1987$; 1986)estimated from their static microcosms, which are likely to have had severe mass transfer effects, but Carter and Jewell (1993)found the $K_{S}$ for PCE (not measured for other chlorinated ethenes) in their expanded-bed reactor to be $0.054 \pm 0.024 \mu \mathrm{M}$, which is not greatly different than the $0.11 \pm 0.04 \mu \mathrm{M}$ found in this study. These half-velocity coefficients are much lower than the $200 \mu \mathrm{M}$ reported for PCE and $240 \mu \mathrm{M}$ for TCE for the tetrachloroethylene reductive dehalogenase enzyme purified from Dehalospirillum multivorans (Neumann et al., 1996)), but are comparable to the reported $10 \mu \mathrm{M}$ for PCE and $4 \mu \mathrm{M}$ for TCE of a

Desulfitobacterium sp. dehalogenase (Miller et al., 1997). The half-velocity coefficient for PCE was found in our culture to be significantly lower than that for the other chlorinated ethenes. Low concentrations of PCE are therefore likely to be quickly dechlorinated to TCE, which in turn would be degraded slower because of the much higher $K_{S}$.

The $K_{S}$ values for TCE, cDCE, and VC are significantly above the maximum contaminant levels (MCLs) for these compounds of 0.038, 0.72, and 0.032 $\mu \mathrm{M}$, respectively (Pontius, 1992). For site cleanup, when the chlorinated ethene concentration levels drop into the low $\mu \mathrm{M}$ range of the MCLs, the dechlorination rate can thus be expected to decrease significantly from maximum values. Both the lower reaction rates $(k X)$ and higher $K_{S}$ values can contribute to the frequent finding in the field of incomplete dehalogenation of PCE to ethene from intrinsic or engineered bioremediation. Also, in situ hydrogen concentrations, where dechlorination is active, are often as low as 2 to $10 \mathrm{nM}$, well below the reported $K_{S}$ values for hydrogen electron donor of 20 to $100 \mathrm{nM}$ (Ballapragada et al., 1997; Smatlak et al., 1996). Thus the combined impact of low electron donor and low electron acceptor concentrations relative to their respective $K_{S}$ values could have an even greater impact on overall dehalogenation rates. For this reason when 
dehalogenation rates are being estimated, the limitations imposed by low concentrations of both the donor and $\mathrm{CAH}$ should be considered.

Also, it should be noted that first-order kinetics are often assumed in numerical models of anaerobic dehalogenation. The results here suggest that zero order kinetics are more appropriate for concentrations above a few $\mu \mathrm{M}$, or above the low $\mathrm{mg} / \mathrm{L}$ range. The best approach, however, is to use Monod kinetics for modeling of $\mathrm{CAH}$ fate.

Competitive Inhibition. The above indicated half-velocity coefficients for this culture were obtained by studying each CAH independently. However, Figure 5 shows that VC inhibits the dechlorination rate of $\mathrm{cDCE}$. A nonlinear least squares analysis of the data using Equation 1 gives a maximum cDCE degradation rate $\left(\hat{\mathrm{q}}_{\mathrm{i}} X\right)$ of $5.9 \pm 0.5 \mu \mathrm{M} / \mathrm{day}$ for the $8.8 \mathrm{mg} / \mathrm{L}$ VSS with an inhibition constant of $3.3 \pm 1.1 \mu \mathrm{M}$ VC when the previously measured cDCE half-velocity coefficient $\left(K_{i}\right)$ of $3.3 \mathrm{M}$ was assumed. The curves in Figure 5 were drawn using Equation 2 with these values for $\mathrm{VC}$ concentrations of 3,8 , and $28 \mu \mathrm{M}$ as measured in the sets of bottles. This VC competitive inhibition constant is within the error bounds of the previously recorded $\mathrm{K}_{\mathrm{j}}$ of $2.6 \pm 1.9 \mu \mathrm{M}$, supporting the assumption that $K_{j}$ could be used for the inhibition constant in Equations 2, 4, and 5. Similarly, cDCE was found to inhibit VC dechlorination with an inhibition constant comparable to its half-velocity coefficient $\left(K_{i}\right)$ as proposed in Equations 2, 4, and 5.

Rosner et al. (1997) also found that cDCE competitively inhibited VC dechlorination when using cell extracts from a VC enrichment culture originally derived from the PCE-utilizing culture used in this study. Competitive inhibition between cDCE and VC with inhibition constants similar to half-velocity coefficients is consistent with a single species that can use either $\mathrm{CAH}$ as an electron acceptor.

VC growth rate. To evaluate the potential for growth when using VC as an electron acceptor, a serial dilution of the culture was made using separate bottles, each fed the same concentration of $\mathrm{VC}$ in the absence of cDCE. The resulting VC depletion curves are shown in Figure 6. A nonlinear least squares fit of the data to Equations 1 and 4 yielded a maximum initial degradation 
rate $\left(\hat{\mathrm{q}}_{\mathrm{j}} X\right)$ of $4.5 \pm 1.1 \mu \mathrm{M} /$ day for the measured $6.2 \mathrm{mg} / \mathrm{L} \mathrm{VSS}$ and a maximum specific growth rate $\left(\hat{\mu}_{\mathrm{j}}\right)$ of $0.21 \pm 0.02$ /day.

At day 50, after VC had been completely dechlorinated to ethene, $4 \mu$ moles of hydrogen and commercial cDCE (60 $\mu \mathrm{M}$ aqueous) were added to the 0.19 and $0.097 \mathrm{mg} / \mathrm{L}$ initial VSS bottles and to a parallel control bottle initially containing $0.097 \mathrm{mg} / \mathrm{L} \mathrm{VSS}$ but no initial VC. Dechlorination of $\mathrm{cDCE}$ proceeded at a rate of $17 \mu \mathrm{M} /$ day between days 51 and 53 in the bottles that had previously received $\mathrm{VC}$ while no $\mathrm{CDCE}$ dechlorination resulted in the control with no prior exposure to $\mathrm{VC}$. The high $\mathrm{cDCE}$ dechlorination rate of $17 \mu \mathrm{M} / \mathrm{day}$ is similar to that obtained with $25 \mathrm{mg} / \mathrm{L} \mathrm{VSS}$ of fresh reactor culture. These results suggest that the same species that grew on $\mathrm{VC}$ was also responsible for cDCE dechlorination, justifying the use of additive growth for the dechlorinating biomass as in Equations 3- 5.

cDCE growth rate. The maximum specific growth rate with $\operatorname{cDCE}\left(\hat{\mu}_{i}\right)$ was also evaluated by serial dilution with the results shown in Figure 7. However, high concentrations of commercial cDCE were found to adversely affect the growth rate (Figure 8). Although no significant inhibitory effect was noted previously in short-term experiments, significant adverse affects were seen on growth and $\mathrm{cDCE}$ utilization with the longer exposure time shown here. At the commercial cDCE concentration of $126 \mu \mathrm{M}$, dechlorination was essentially absent.

This inhibition of growth rate by commercial cDCE was modeled using an inhibition constant $(\Lambda)$ in Equation 4. Nonlinear least squares estimates using equations 1 and 4 with the Figure 8 data give a specific inhibition constant $(\Lambda)$ of $0.0034 \pm 0.0006 / \mu \mathrm{M} \cdot$ day and maximum specific growth rate $\left(\hat{\mu}_{i}\right)$ of $0.45 \pm 0.09 /$ day. The curves in Figure 8 were drawn using these best fit estimates. To illustrate how the model predicts the transition through VC to ethene, the time course for four of the bottles from which the data for Figure 8 was obtained are shown in Figure 9 along with the model predictions. With the coefficients obtained, Equation 4 indicates the organism net growth rate would become negative for commercial cDCE concentrations over 130 $\mu \mathrm{M}$. 
Two control bottles associated with the Figure 8 experiment were initially prepared with no cDCE added. In the absence of commercial cDCE, significant methane was produced. At day 80 these two bottles and the 41 and $51 \mu \mathrm{M}$ initial cDCE bottles, which had completed dechlorination to ethene, received $60 \mu \mathrm{M}$ of commercial cDCE along with a refeeding of benzoate, yeast extract, and hydrogen as initially. The two bottles that were previously exposed to $\mathrm{cDCE}$ dechlorinated $\mathrm{cDCE}$ at $14 \mu \mathrm{M}$ /day from day 81 to 82 . The two bottles that had no cDCE, however, showed no significant cDCE dechlorination within 10 days. These and the previous results suggest that growth is associated with both $\mathrm{cDCE}$ and $\mathrm{VC}$ dehalogenation.

Additionally, in the Figure 8 experiment, methane production was observed in only the 19 and $27 \mu \mathrm{M}$ initial cDCE bottles. To further examine the influence of commercial cDCE on methane production, varying amounts of commercial cDCE were added to a series of bottles all containing $4.5 \mathrm{mg} / \mathrm{L} \mathrm{VSS}$ of reactor culture and excess hydrogen. Figure 10 shows the inhibitory effects of commercial cDCE on methane production. Even with substantially more biomass added to the bottles, commercial cDCE inhibition was sufficient to stop methane production within days when high concentrations were added, indicating that the commercial cDCE was even more inhibitory to methanogens than to dechlorinators. Since hydrogen remained in excess for the bottles in which 256 M or more of cDCE was added, decreased methane production did not appear to be the result of competition for hydrogen.

A nonlinear least squares analysis of Figure 7 data using the specific inhibition constant derived from Figure 8 data gives a $\hat{\mu}_{\mathrm{i}}$ of $0.30 \pm 0.06 /$ day. This $\hat{\mu}_{\mathrm{i}}$ is somewhat less than that derived from the Figure 8 results, which was designed primarily to estimate the specific inhibition constant, $\Lambda$.

Biogenic cDCE. As illustrated in Figure 11, commercial cDCE transformation slowed and then stopped while biogenic cDCE was completely consumed. In another study, no adverse effect of high biogenic cDCE concentrations on cDCE dehalogenation rates was observed (Figure 12). The maximum specific growth rate deduced from Figure 12 data was $0.23 \pm 0.15$ /day, independent of the initial concentration of biogenic cDCE. 
While commercial cDCE inhibited culture growth, biogenic cDCE did not. Since the inhibition was proportional to the amount of commercial cDCE added, it appears that the inhibition resulted from an unknown contaminant in the commercial cDCE. GC/MS analysis of the commercial cDCE failed to reveal any contaminant likely to be the cause.

\section{Discussion}

In order to predict dehalogenation in the field following bioaugmentation or the addition of a potential electron donor source, or in a bioreactor, information is needed on factors affecting the growth rate of the cDCE and $\mathrm{VC}$-dechlorinating microorganisms and the interactive effects between the dehalogenated CAHs. For this purpose $\mathrm{CAH}$ utilization and microorganism growth models were developed and evaluated with a laboratory mixed culture of PCE-dehalogenate organisms. The models include competitive inhibition between cDCE and VC as observed. Such competitive inhibition significantly slows the dehalogenation of $\mathrm{CDCE}$ as VC is produced, and the presence of $\mathrm{CDCE}$ in turn inhibits the dechlorination rate of $\mathrm{VC}$. The inhibition constants were found comparable to their respective half-velocity coefficients, which is consistent with the assumption of a single species that can use either cDCE or VC or both as an electron acceptor.

More definitive evidence that a single species dehalogenated both $\mathrm{cDCE}$ and VC is provided by the finding that a culture grown on VC from a small seed $(0.097 \mathrm{mg} / \mathrm{L})$ over an 80 day period then dehalogenated cDCE at a rate much faster than obtained with $3.5 \mathrm{mg} / \mathrm{L}$ of original seed. A control with no VC present over the same 80 day period did not dechlorinate cDCE. This indicates VC was used for growth by the dehalogenating organisms, and the cultures grown on VC simultaneously had the ability for cDCE dehalogenation.

Table 6 includes these coefficients along with values reported for other cultures for comparison. Maximum specific dechlorination rates vary widely because mixed culture biomass concentrations measured as VSS are generally a very poor measure of the active dehalogenation population. Such values are very culture dependent and should be used with caution. Maximum specific growth rates, however, are not dependent on biomass measurements and thus are more reliable. The maximum specific growth rate on $\mathrm{VC}\left(\hat{\mu}_{\mathrm{j}}\right)$ was determined to be $0.21 \pm 0.02$ /day 
for this culture. For comparison, Rosner et al. (Rosner et al., 1997) found a growth rate on VC of 0.45 /day in her cultures fed hydrogen, acetate, and yeast extract in the presence of $1 \mathrm{mM} 2-$ bromoethanesulfonic acid to inhibit methanogenesis. Tonnaer et al. (1997)used a VC growth rate of 0.18 /day, comparable to the one determined in this study, to fit PCE dechlorination data with their model, which assumes that different organisms degrade VC and cDCE. In contrast, the dehalogenating culture containing Dehalococcoides ethenogenes Strain 195 dechlorinates VC cometabolically without growth (Fennell and Gossett, 1998; Maymo-Gatell et al., 1997; Tandoi et al., 1994).

The growth model presented here as Equations 3 and 4 includes duel limitations based upon both electron donor and electron acceptor concentrations. Growth with two possible electron acceptors is indicated by additive growth terms, as also used by Bagley and Tonnaer et al. in their models. However, they did not include the terms for competitive inhibition for the electron acceptors. The question arises as to whether growth rate with both electron acceptors present is greater than with either alone. With competitive inhibition included, it is not. Indeed, the net maximum specific growth rate in the absence of decay, varies linearly from $\hat{\mu}_{i}$ to $\hat{\mu}_{j}$ as the relative fraction of the molar concentration of VC to the sum of VC plus cDCE increases from zero to one.

Commercial cDCE was found to inhibit growth in proportion to the amount of cDCE added. Biologically generated cDCE did not similarly inhibit growth, suggesting the presence of an unknown toxic contaminant in the commercial cDCE. An inhibition term, $\Lambda$, was used in the Equation 4 model to account for this effect. Over the concentrations range used, an inhibition term $(\Lambda$ for the $\mathrm{cDCE}$ added of $0.0034 \pm 0.0006 / \mu \mathrm{M} \cdot$ day was found along with a maximum specific growth rate $\left(\hat{\mu}_{\mathrm{i}}\right)$ for $\mathrm{cDCE}$ of $0.45 \pm 0.09$ /day. Applying this $\Lambda$ to the initial biomass dilutions illustrated in Figure7 gave a maximum specific growth rate $\left(\hat{\mu}_{i}\right)$ of $0.30 \pm 0.06$ /day. These cDCE maximum growth rates are somewhat higher than the VC maximum growth rate found here, although it is comparable to the VC growth rate reported by Rosner et al. (Rosner et al., 1997). Fennell and Gossett (1998) estimated a maximum cDCE growth rate of 0.44 /day for their culture, which is comparable to the growth rates found here. Thus, maximum growth rates 
for $\mathrm{CDCE}$ and $\mathrm{VC}$ reported by different investigators are quite similar, generally varying between about 0.2 and 0.45 day $^{-1}$.

While an inhibition term was used here for commercial cDCE, such addition is not necessary for model use at contaminated sites since the CDCE that would be found there would be biogenic cDCE, for which no inhibition was noted at the concentrations here used. For practical purposes, the general models given by Equations 1 and 3 should be useful. 


\section{TABLES}

Table 1. Localization of the VC dehalogenating activity. Activities were determined as described under Materials and Methods.

\begin{tabular}{|c|c|c|c|}
\hline & VC dehalogenating activity & ATPase & Malate dehydrogenase \\
\hline Fraction & $\begin{array}{l}\text { Total activity } \\
\\
\qquad \mathrm{nmol} \mathrm{min}{ }^{-1}(\%)\end{array}$ & $\begin{array}{l}\text { Total Activity } \\
\operatorname{nmol~} \min ^{-1}(\%)\end{array}$ & $\begin{array}{l}\text { Total activity } \\
\quad \text { nmol } \min ^{-1}(\%)\end{array}$ \\
\hline Cell free extract & $27(100)$ & $940(100)$ & $53(100)$ \\
\hline Cytoplasmic fraction & $2(7)$ & $350(37)$ & $35(66)$ \\
\hline Membrane fraction & $17(63)$ & $430(46)$ & $2(4)$ \\
\hline
\end{tabular}

Table 2. Mass Balance for CSTR over a Two-Day Period.

\begin{tabular}{|c|c|c|c|c|}
\hline Parameter & $\begin{array}{c}\text { Mass } \\
\text { change }^{\mathrm{d}} \\
(\mu \mathrm{mol})\end{array}$ & $\begin{array}{c}\text { Electron } \\
\text { equivalent factor }\end{array}$ & $\begin{array}{c}\text { Electron } \\
\text { equivalents } \\
\text { consumed }(\mu \mathrm{eq})\end{array}$ & $\begin{array}{c}\text { Electron } \\
\text { equivalents } \\
\text { formed }(\mu \mathrm{eq})\end{array}$ \\
\hline Benzoate & -323 & 30 & -9690 & \\
\hline Yeast extract $^{\mathrm{a}}$ & -35 & 20 & -700 & 7200 \\
\hline Acetate & 900 & 8 & & 360 \\
\hline Biomass & 18 & 20 & & 1288 \\
\hline Methane & 161 & 8 & & 912 \\
\hline Ethene & 114 & 8 & & 9760 \\
\hline Total & & & -10390 & \\
\hline
\end{tabular}

${ }^{a}$ Calculated by assuming yeast extract as $\mathrm{C}_{5} \mathrm{H}_{7} \mathrm{O}_{2} \mathrm{~N}$.

${ }^{b}$ The empirical formula of $\mathrm{C}_{5} \mathrm{H}_{7} \mathrm{O}_{2} \mathrm{~N}$ for bacterial cells was used in the calculation of biomass. Biomass concentration in the CSTR was $10 \mathrm{mg}$ (dry weight) per liter.

${ }^{c}$ The electron equivalents for dehalogenation were calculated from ethene production rather than from PCE addition as some PCE may have been lost through rubber tubing during feeding.

${ }^{\mathrm{d}}$ Negative and positive values represent consumption and production, respectively. 
Table 3. Threshold $\mathrm{H}_{2}$ concentration and energetics of $\mathrm{H}_{2}$ utilization reactions.

\begin{tabular}{|c|c|c|c|}
\hline \multirow{2}{*}{$\begin{array}{c}\text { Biological } \\
\text { processes }\end{array}$} & Equation & $\begin{array}{c}\text { Threshold } \\
\mathrm{H}_{2} \text { conc. } \\
\text { in liquid } \\
\text { phase } \\
(\mathrm{nM})\end{array}$ & $\begin{array}{c}\text { Energy } \\
\text { available at } \\
\text { threshold } \mathrm{H}_{2} \\
\text { conc. } \text {, c } \\
\left(\mathrm{kJ} / \mathrm{mol} \mathrm{H}_{2}\right)\end{array}$ \\
\hline $\begin{array}{c}\text { Dehalo- } \\
\text { genation }\end{array}$ & $\mathrm{cDCE}+\mathrm{H}_{2}=\mathrm{VC}+\mathrm{H}^{+}+\mathrm{Cl}^{-}$ & 2 & -115.5 \\
\cline { 2 - 3 } & $\mathrm{VC}+\mathrm{H}_{2}=\mathrm{ETH}+\mathrm{H}^{+}+\mathrm{Cl}^{-}$ & & -129.3 \\
\cline { 2 - 4 } $\begin{array}{c}\text { Methano- } \\
\text { genesis }\end{array}$ & $0.25 \mathrm{CO}_{2}+\mathrm{H}_{2}=0.25 \mathrm{CH}_{4}+0.5 \mathrm{H}_{2} \mathrm{O}$ & 11 & -5.8 \\
\hline $\begin{array}{l}\text { Homo- } \\
\text { acetogenesis }\end{array}$ & $0.5 \mathrm{CO}_{2}+\mathrm{H}_{2}=0.25 \mathrm{CH}_{3} \mathrm{COO}^{-}+0.25 \mathrm{H}^{+}$ & $400^{\mathrm{a}}$ & -6.8 \\
\hline
\end{tabular}

${ }^{a}$ Data for Acetobacterium woodii (31).

${ }^{\mathrm{b}}$ Under experimental condition when $\mathrm{PCO}_{2}=0.2 \mathrm{~atm}, \mathrm{PCH}_{4}=0.05 \mathrm{~atm}$, [acetate $]=2 \mathrm{mM},\left[\mathrm{Cl}^{-}\right]=$ $0.02 \mathrm{M},[\mathrm{cDCE}]=1 \mu \mathrm{M}$ (in headspace), $[\mathrm{VC}]=20 \mu \mathrm{M}$ (in headspace). $\left[\mathrm{H}_{2}\right]=\mathrm{H}_{2}$ threshold concentration.

c All calculations are based upon published tables (Dolfing and Janssen, 1994; Thauer, et al., 1977). 
Table 4. Ratio of headspace $(\mu \mathrm{M})$ to aqueous $(\mu \mathrm{M})$ concentration for each CAH measured at the beginning and end of batch experiments, and the reported dimensionless Henry's law at $25^{\circ} \mathrm{C}$. Although $\mathrm{CAH}$ concentrations decreased during the experiments, the ratios did not change significantly, suggesting good mass transfer between gas and liquid phases during the experiments.

\begin{tabular}{|c|c|c|c|}
\hline & \multicolumn{2}{|c|}{$\begin{array}{c}\text { Ratio of headspace to } \\
\text { aqueous concentrations }\end{array}$} & Dimensionless Henry's \\
& Initial & Final & $\begin{array}{c}\text { Law coefficient } \\
\text { (Gossett, 1987) }\end{array}$ \\
\hline PCE & $0.71 \pm 0.07$ & $0.73 \pm 0.05$ & 0.72 \\
\hline TCE & $0.40 \pm 0.05$ & $0.41 \pm 0.04$ & 0.39 \\
\hline cDCE & $0.19 \pm 0.03$ & $0.18 \pm 0.04$ & 0.15 \\
\hline VC & $1.03 \pm 0.10$ & $1.04 \pm 0.09$ & 1.07 \\
\hline
\end{tabular}

Table 5. Half-velocity coefficients $\left(K_{S}\right)$ and maximum aqueous dechlorination rates $(k X)$ with their $95 \%$ confidence intervals for each of the chlorinated ethenes with $38 \mathrm{mg} / \mathrm{L} \mathrm{VSS}$. The apparent $k\left(k_{a p p}\right)$ assuming $X$ is equal to VSS is also provided.

\begin{tabular}{|c|c|c|c|}
\hline & $\begin{array}{c}K X \\
(\mu \mathrm{M} / \text { day })\end{array}$ & $\begin{array}{c}k_{\text {app }} \\
(\mu \mathrm{mol} / \mathrm{mgVSS} \cdot \mathrm{d})\end{array}$ & $\begin{array}{c}K_{S} \\
(\mu \mathrm{M})\end{array}$ \\
\hline $\mathrm{PCE}$ & $77 \pm 5$ & $2.0 \pm 0.1$ & $0.11 \pm 0.04$ \\
\hline $\mathrm{TCE}$ & $59 \pm 11$ & $1.6 \pm 0.3$ & $1.4 \pm 0.9$ \\
\hline $\mathrm{cDCE}$ & $14 \pm 3$ & $0.37 \pm 0.08$ & $3.3 \pm 2.2$ \\
\hline $\mathrm{VC}$ & $13 \pm 3$ & $0.34 \pm 0.08$ & $2.6 \pm 1.9$ \\
\hline
\end{tabular}


Table 6. Kinetic coefficients for anaerobic dehalogenation.

\begin{tabular}{|c|c|c|c|c|}
\hline $\begin{array}{l}\text { Coeff- } \\
\text { icient }\end{array}$ & Description & Value & Units & Source \\
\hline$\hat{\mathrm{q}}_{\mathrm{PCE}}$ & $\begin{array}{l}\text { Maximum specific } \\
\text { dechlorination rate of PCE } \\
\text { to TCE }\end{array}$ & $\begin{array}{c}12 \\
2.0 \\
2.7,4.6\end{array}$ & $\frac{\mu m o l P C E}{m g V S S \cdot d a y}$ & $\begin{array}{l}\text { (Sharma and McCarty, 1996) } \\
\text { This study } \\
\text { (Tandoi et al., 1994) }\end{array}$ \\
\hline$\hat{\mathrm{q}}_{\mathrm{TCE}}$ & \begin{tabular}{|l|} 
Maximum specific \\
dechlorination rate of \\
TCE to cDCE \\
\end{tabular} & $\begin{array}{l}1.6 \\
7.7\end{array}$ & $\frac{\mu m o l T C E}{m g V S S \cdot d a y}$ & $\begin{array}{l}\text { This study } \\
\text { (Tandoi et al., 1994) }\end{array}$ \\
\hline$\hat{\mathrm{q}}_{\mathrm{CDCE}}$ & $\begin{array}{l}\text { Maximum specific } \\
\text { dechlorination rate of } \\
\text { cDCE to VC }\end{array}$ & $\begin{array}{l}0.6 \\
5.7\end{array}$ & $\frac{\mu m o l c D C E}{m g V S S \cdot d a y}$ & $\begin{array}{l}\text { This study, Figures 5,7 } \\
\text { (Tandoi et al., 1994) }\end{array}$ \\
\hline$\hat{\mathrm{q}}_{\mathrm{vc}}$ & $\begin{array}{l}\text { Maximum specific } \\
\text { dechlorination rate of } \mathrm{VC}\end{array}$ & $\begin{array}{l}0.6 \\
4.7\end{array}$ & $\frac{\mu m o l ~ V C}{m g V S S \cdot d a y}$ & $\begin{array}{l}\text { This study, Figure } 6 \\
\text { (Tandoi et al., 1994) }\end{array}$ \\
\hline $\mathrm{K}_{\mathrm{PCE}}$ & $\begin{array}{l}\text { Half-velocity coefficient } \\
\text { for PCE dehalogenation }\end{array}$ & $\begin{array}{c}0.11 \\
0.05 \\
2.8 \\
10 \\
200 \\
\end{array}$ & $\mu \mathrm{M}$ & $\begin{array}{l}\text { This study } \\
\text { (Carter and Jewell, 1993) } \\
\text { (Ballapragada et al., 1997) } \\
\text { (Miller et al., 1997) } \\
\text { (Neumann et al., 1996) }\end{array}$ \\
\hline $\mathrm{K}_{\mathrm{TCE}}$ & $\begin{array}{l}\text { Half-velocity coefficient } \\
\text { for TCE dehalogenation }\end{array}$ & $\begin{array}{c}1.4 \\
1.5 \\
4 \\
240\end{array}$ & $\mu \mathrm{M}$ & $\begin{array}{l}\text { This study } \\
\text { (Ballapragada et al., 1997) } \\
\text { (Miller et al., 1997) } \\
\text { (Neumann et al., 1996) }\end{array}$ \\
\hline $\mathrm{K}_{\mathrm{cDCE}}$ & $\begin{array}{l}\text { Half-velocity coefficient } \\
\text { for cDCE dehalogenation }\end{array}$ & $\begin{array}{l}3.3 \\
3.0\end{array}$ & $\mu \mathrm{M}$ & $\begin{array}{l}\text { This study } \\
\text { (Ballapragada et al., 1997) }\end{array}$ \\
\hline $\mathrm{K}_{\mathrm{VC}}$ & $\begin{array}{l}\text { Half-velocity coefficient } \\
\text { for VC dehalogenation }\end{array}$ & $\begin{array}{l}2.6 \\
360\end{array}$ & $\mu \mathrm{M}$ & $\begin{array}{l}\text { This study } \\
\text { (Ballapragada et al., 1997) }\end{array}$ \\
\hline $\mathrm{K}_{\mathrm{H}}$ & $\begin{array}{l}\text { Half-velocity coefficient } \\
\text { for } \mathrm{H}_{2} \text { consumption }\end{array}$ & $\begin{array}{r}9-21 \\
100\end{array}$ & $\mathrm{nM}$ & $\begin{array}{l}\text { (Ballapragada et al., 1997) } \\
\text { (Smatlak et al., 1996) }\end{array}$ \\
\hline$S_{H}^{*}$ & $\begin{array}{l}\text { Hydrogen threshold for } \\
\text { dehalogenation }\end{array}$ & $\begin{array}{l}2 \\
2 \\
\end{array}$ & $\mathrm{nM}$ & $\begin{array}{l}\text { (Fennell and Gossett, 1998) } \\
\text { (Yang and McCarty, 1998) }\end{array}$ \\
\hline$\hat{\mu}_{\mathrm{PCE}}$ & $\begin{array}{l}\text { Maximum growth rate on } \\
\text { PCE dechlorination }\end{array}$ & $\begin{array}{l}0.9 \\
0.9 \\
6.7 \\
2.0\end{array}$ & day $^{-1}$ & $\begin{array}{l}\text { (Holliger et al., 1998) } \\
\text { (Maymo-Gatell et al., 1997) } \\
\text { (Scholz-Muramatsu, et al., } \\
\text { 1990) } \\
\text { (Gerritse, et al., 1996) }\end{array}$ \\
\hline$\hat{\mu}_{\mathrm{CDCE}}$ & $\begin{array}{l}\text { Maximum growth rate on } \\
\text { cDCE dechlorination }\end{array}$ & $\begin{array}{l}0.23 \\
0.30 \\
0.45 \\
0.44 \\
\end{array}$ & day $^{-1}$ & $\begin{array}{l}\text { This study, Figure } 12 \\
\text { This study, Figure } 7 \\
\text { This study, Figure } 8 \\
\text { (Fennell and Gossett, 1998) }\end{array}$ \\
\hline$\hat{\mu}_{\mathrm{vc}}$ & $\begin{array}{l}\text { Maximum growth rate on } \\
\text { VC dechlorination }\end{array}$ & $\begin{array}{l}0.21 \\
0.18 \\
0.45\end{array}$ & day $^{-1}$ & $\begin{array}{l}\text { This study, Figure } 6 \\
\text { (Tonnaer et al., 1997) } \\
\text { (Rosner et al., 1997) }\end{array}$ \\
\hline
\end{tabular}




\section{FIGURES}

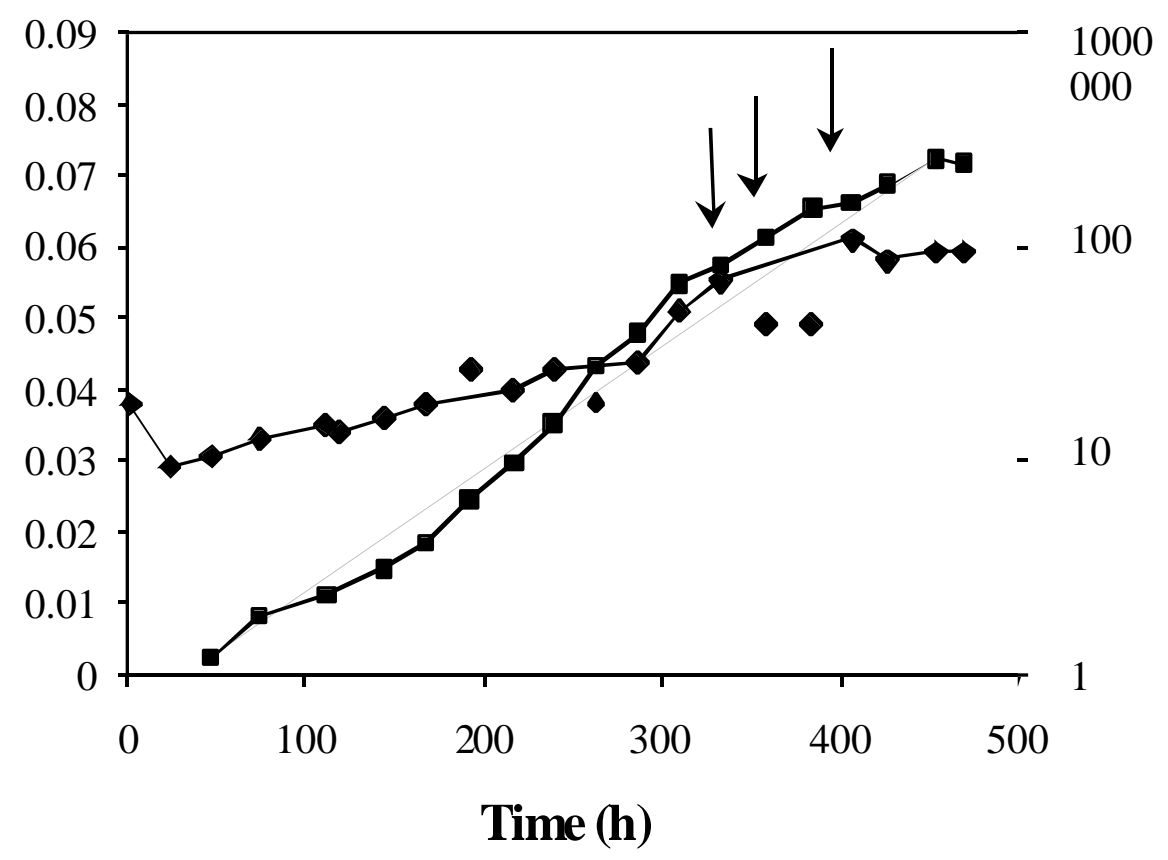

Figure 1. Optical density $(\diamond)$ and cumulative ethene formation ( $\boldsymbol{\square}$, total amount) in an anaerobic mixed 1L-culture grown in the presence of vinyl chloride (initial concentration in liquid $50 \mu \mathrm{M}$ (total amount $110 \mu \mathrm{mol}$ )) and $\mathrm{H}_{2} / \mathrm{CO}_{2}$. In addition, the medium contained $1 \mathrm{mM}$ acetate, $1 \mathrm{mM}$ BESA, and $0.001 \%$ yeast extract. At the times indicated by arrows, the culture was amended with additional vinyl chloride gas $(120 \mu \mathrm{mol})$. Note the log-scale for ethene formation. 


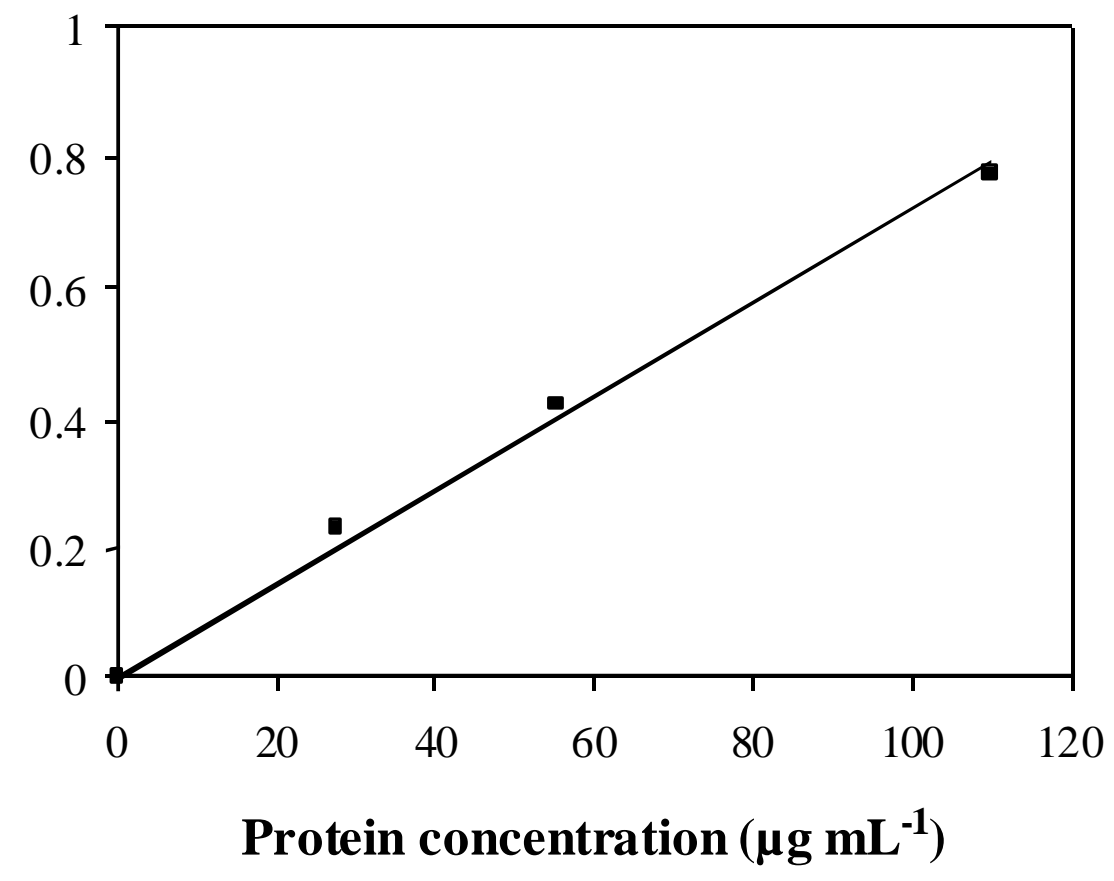

Figure 2. Protein dependence of ethene formation from VC catalyzed by cell-free extract of the mixed culture. Titanium(III) citrate-reduced methyl viologen served as the electron donor. The reaction was started by the addition of $2 \mu \mathrm{mol} \mathrm{VC}$ gas (concentration in liquid $0.4 \mathrm{mM}$ ). Rates were calculated from the initial linear increase of the total amount of ethene. Values are means of duplicate experiments. 


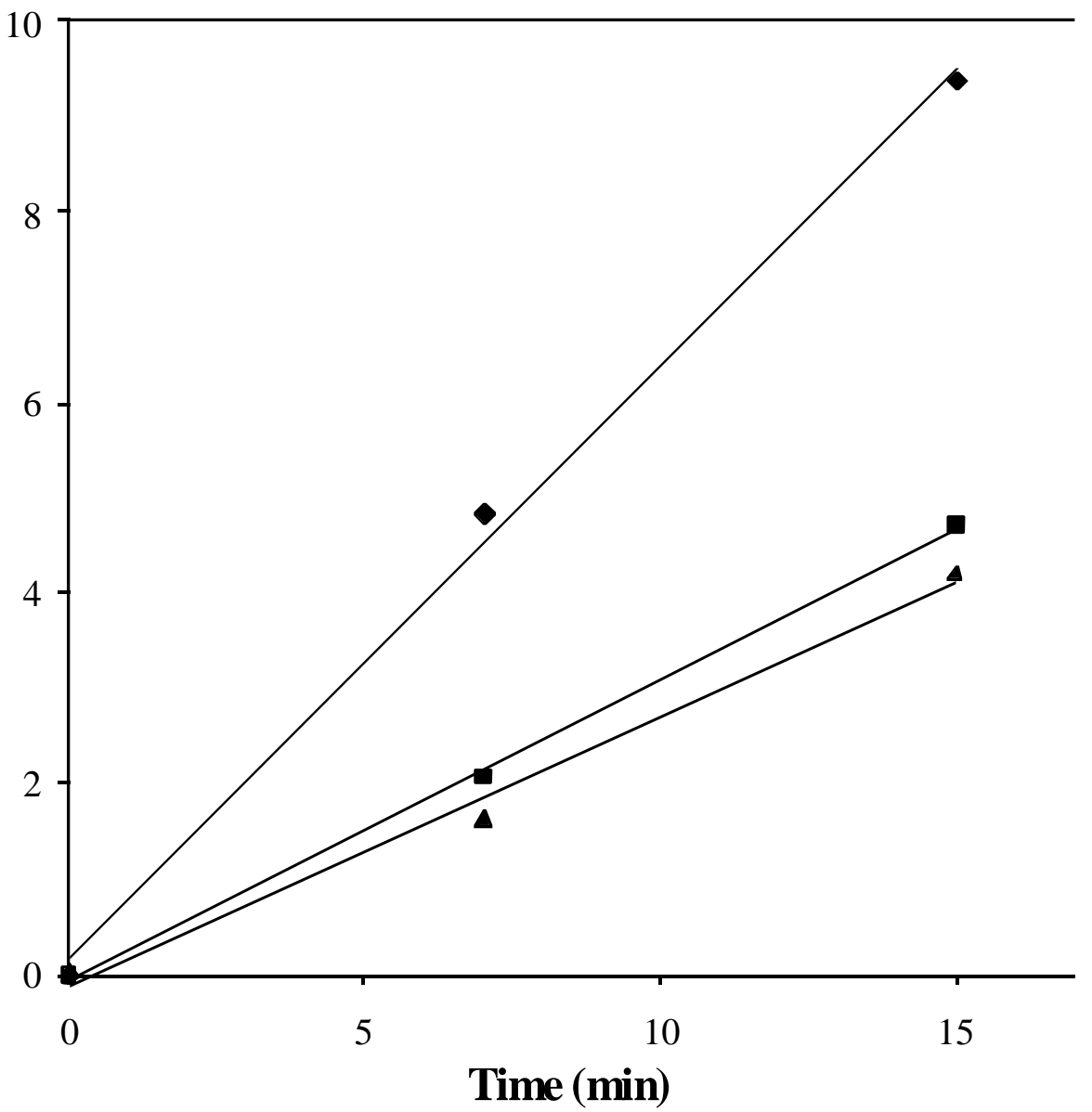

Figure 3. Effect of propyl iodide on reductive VC dehalogenation. Ethene formation from VC

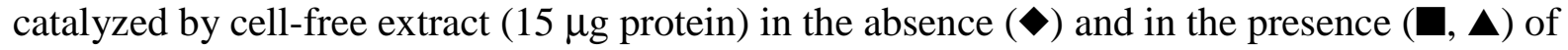
$100 \mu \mathrm{M}$ propyl iodide. In assays with propyl iodide, the cell-free extract had been incubated for $10 \mathrm{~min}$ in the dark ( $\mathbf{\square}$ ) or had been incubated for $10 \mathrm{~min}$ in the dark and subsequently illuminated for $2 \min (\mathbf{\Delta})$ before the assay was started by the addition of $2 \mu$ mol vinyl chloride gas . 

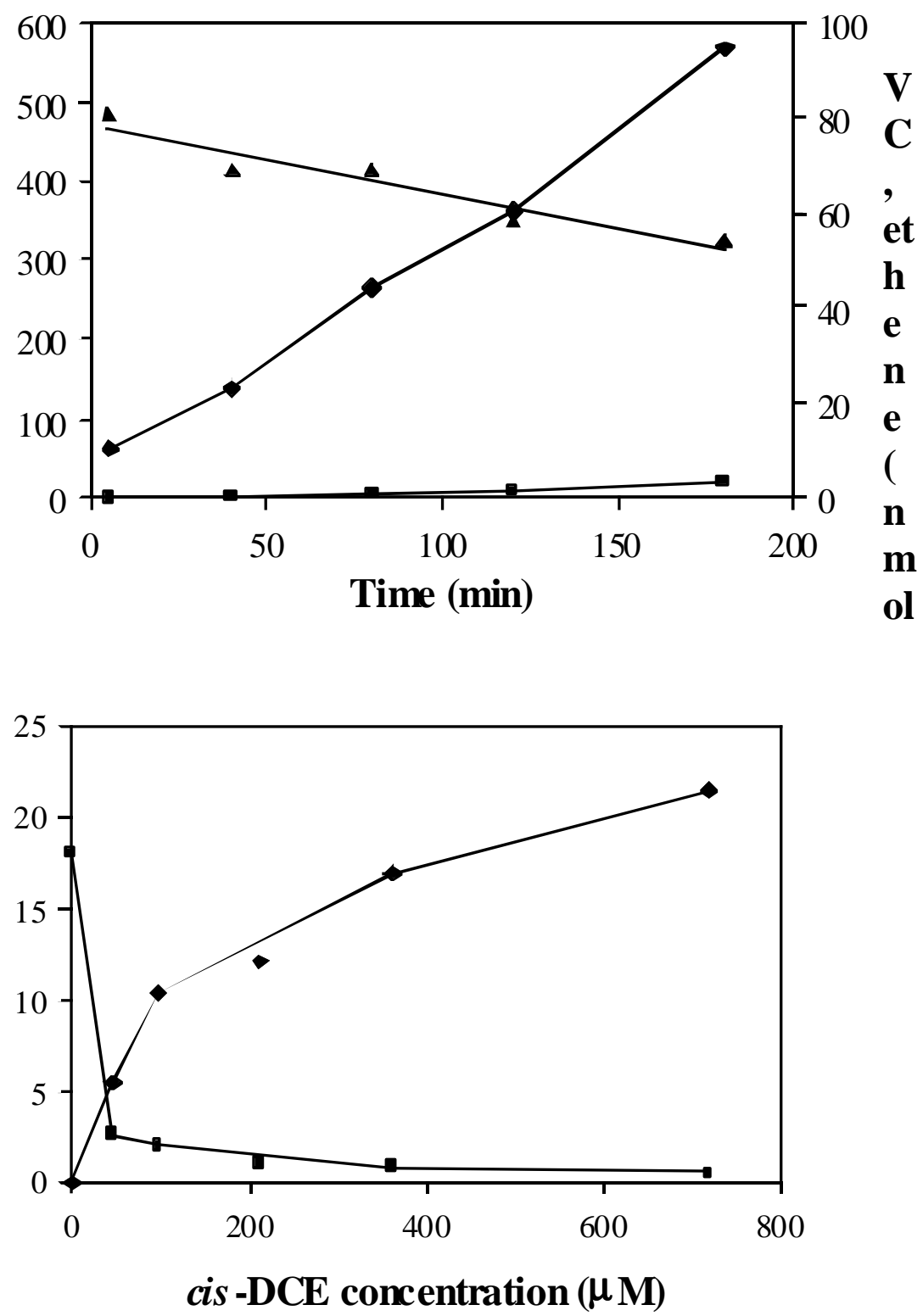

Figure 4. Kinetics of cis-DCE transformation.

(A) Reductive dehalogenation of $c i s$-DCE ( $\mathbf{\Delta})$ by cell-free extracts of the mixed culture. The assay mixture contained $300 \mu \mathrm{M}$ cis-DCE. The assay was started by addition of cell-free extract (30 $\mu \mathrm{g}$ protein). Titanium(III) citrate-reduced methyl viologen served as the electron donor. The formation of $\mathrm{VC}(\diamond)$ and ethene $(\boldsymbol{\square})$ was measured by GC/FID.

(B) Effect of cis-DCE concentrations (initial concentration in liquid) on VC ( $\bullet$ ) and ethene (ם) formation from cis-DCE. The assay was started by addition of cell-free extract ( $90 \mu \mathrm{g}$ protein). Rates were calculated from the initial linear increase of the total amount of $\mathrm{VC}$ and ethene, respectively. 


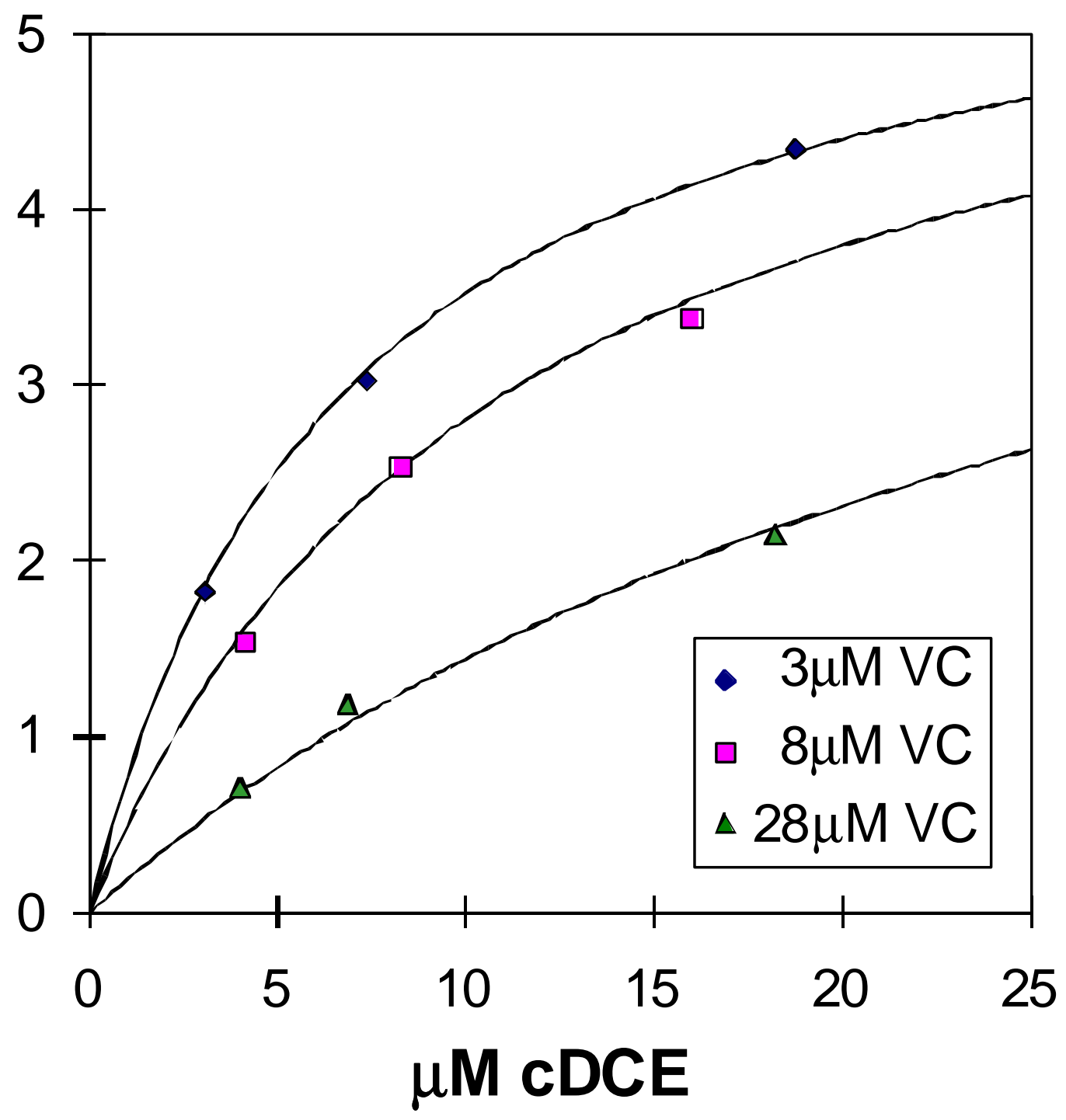

Figure 5. Influence of $\mathrm{VC}$ on the initial dechlorination rate of cDCE. Curves were drawn using the competitive inhibition model (Equation 2) with a nonlinear least squares best fit estimate of the inhibition constant of $3.3 \pm 1.1 \mu \mathrm{M}$. This is comparable with its half-velocity coefficient of $2.6 \pm 1.9 \mu \mathrm{M}$. 


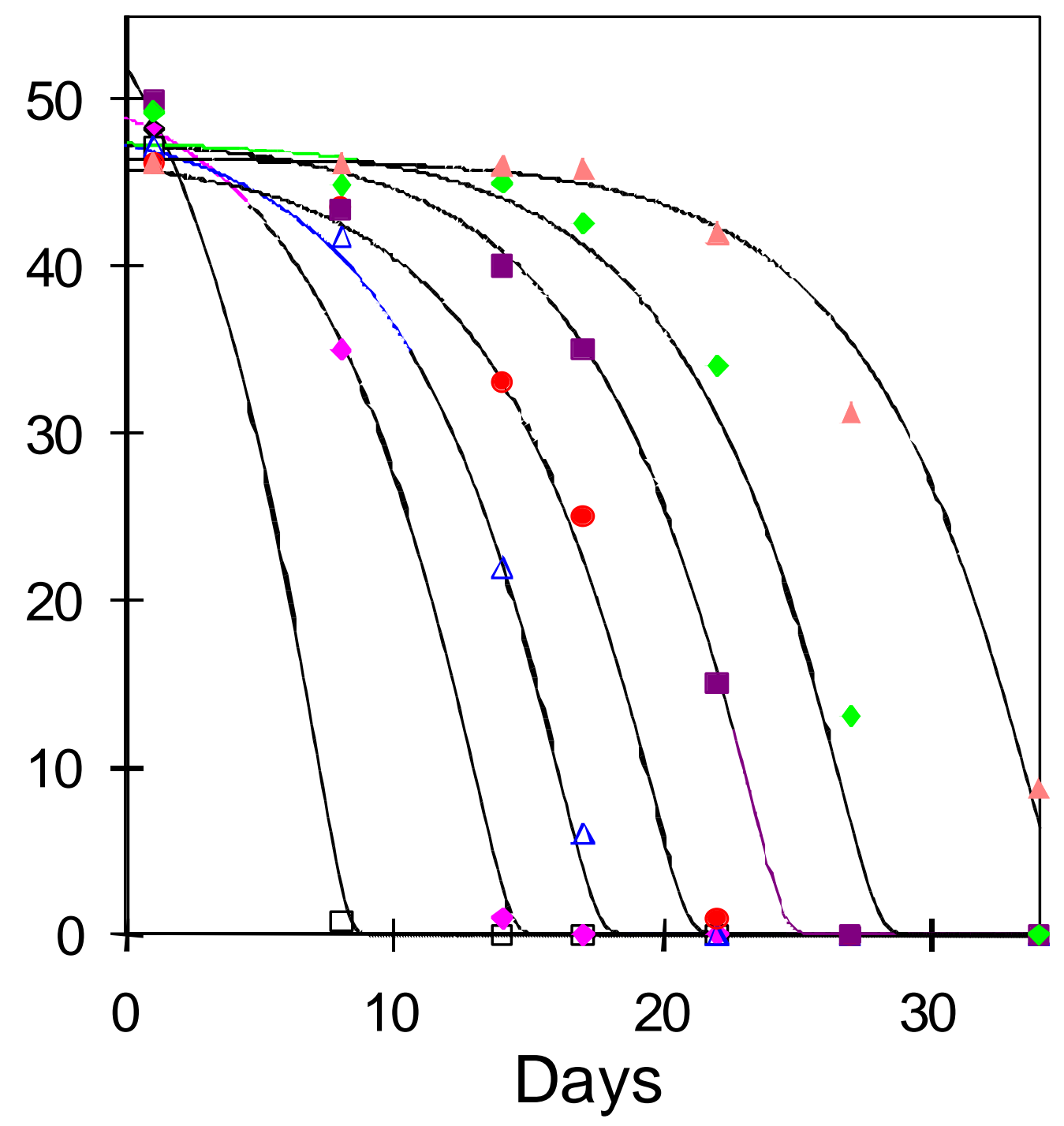

Figure 6. Drawdown curves for VC-fed bottles with initial biomass concentrations of 6.2, 1.6, $0.78,0.39,0.19,0.097$, and $0.081 \mathrm{mg} / \mathrm{L}$ VSS respectively. Curves were drawn using Equations 2 and 5 with a nonlinear least squares best fit estimate of the maximum specific growth rate $\left(\hat{\mu}_{j}\right)$ of $0.21 \pm 0.02 /$ day. 


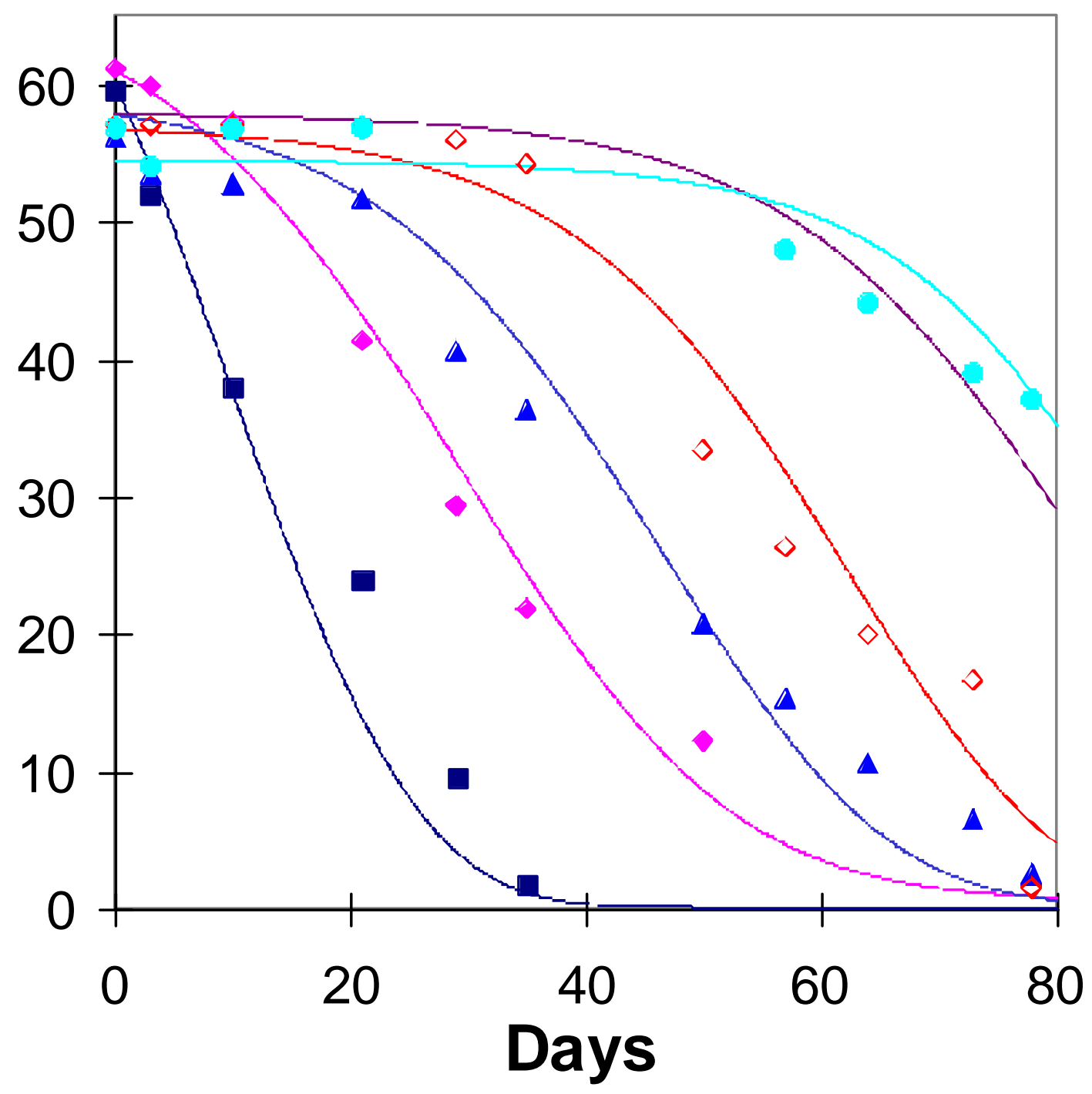

Figure 7. Drawdown curves for cDCE-fed bottles with initial biomass concentrations of 3.5, $0.87,0.22,0.054,0.014$, and $0.0034 \mathrm{mg} / \mathrm{L}$ VSS respectively. Curves were drawn using Equations 2 and 5 with a nonlinear least squares best fit estimate of the maximum specific growth rate $\left(\hat{\mu}_{i}\right)$ of $0.30 \pm 0.06 /$ day for an inhibitory constant $(\Lambda)$ of $0.0034 / \mu \mathrm{M} \cdot$ day. 


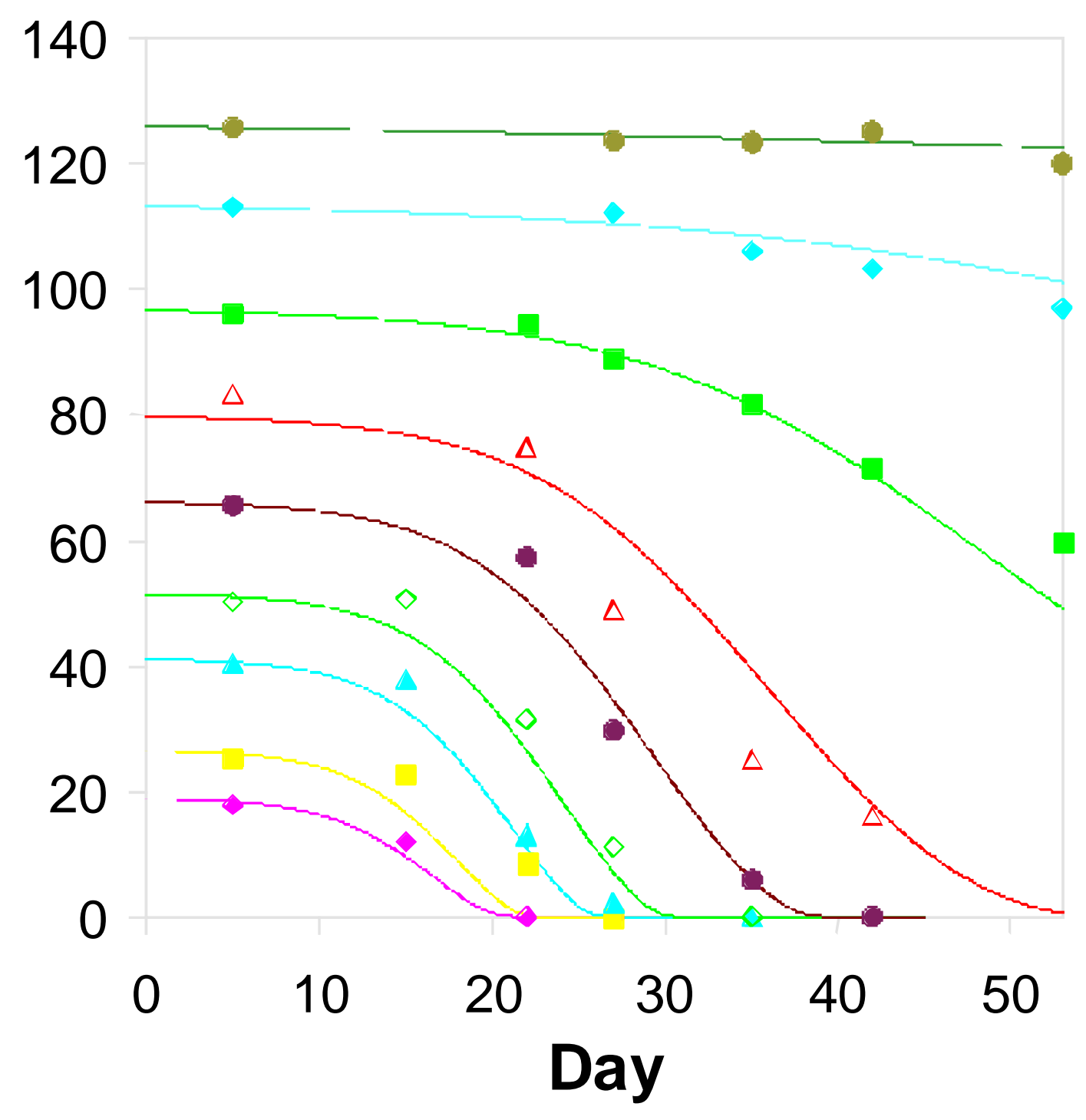

Figure 8. Drawdown curves for cDCE-fed bottles with varying initial concentrations of manufactured cDCE. All bottles were inoculated with $76 \mu \mathrm{g} / \mathrm{L}$ VSS of the mixed culture. Curves represent the fit of the model using a nonlinear least squares best fit estimate of the maximum specific growth rate $\left(\hat{\mu}_{i}\right)$ of $0.45 \pm 0.09$ /day and specific lethality constant $(\Lambda)$ of $0.0034 \pm 0.0006 / \mu \mathrm{M} \cdot \mathrm{day}$. 

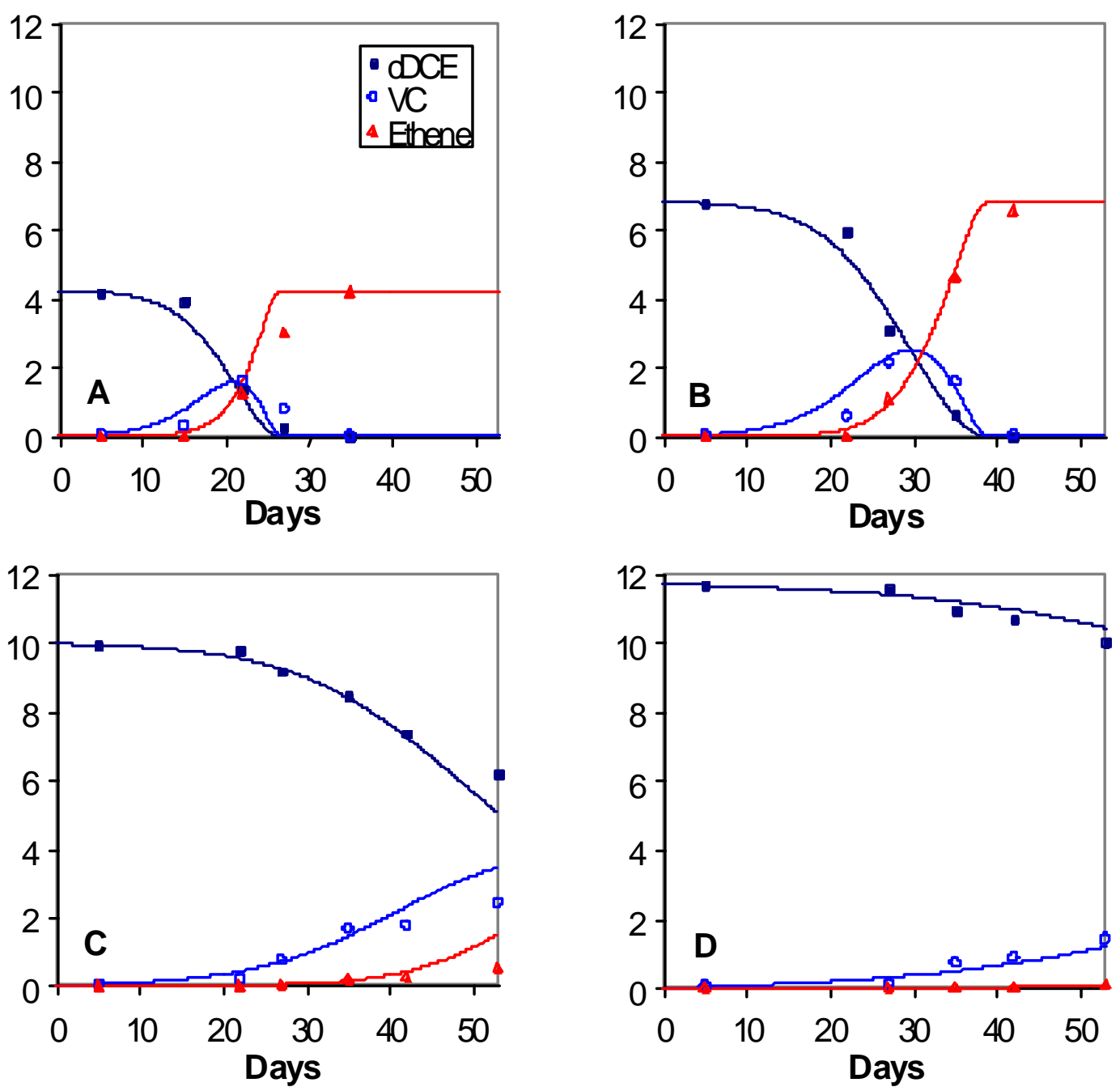

Figure 9. Time course for the bottles represented in Figure 8 initially containing aqueous commercial cDCE concentrations of $41 \mu \mathrm{M}$ (A), $66 \mu \mathrm{M}$ (B), $96 \mu \mathrm{M}$ (C), and $113 \mu \mathrm{M}$ (D). Curves represent the model predictions using a $\hat{\mu}_{i}$ of $0.45 /$ day, $\hat{\mu}_{j}$ of $0.21 /$ day, and $\Lambda$ of $0.0034 / \mu \mathrm{M}$.day. Total micromoles of CAH in the bottle as calculated from headspace measurements and Henry's Law constants are shown. 


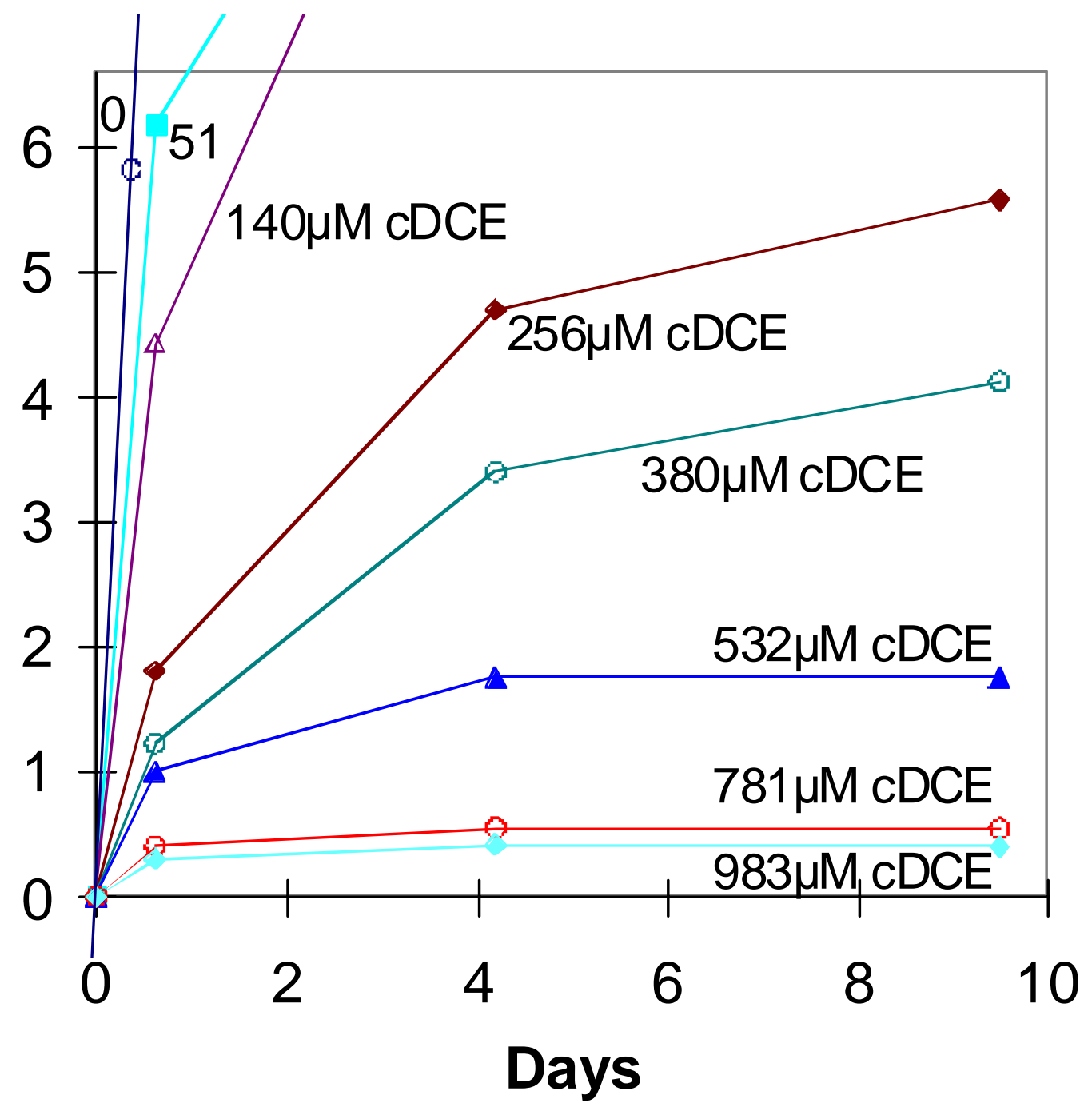

Figure 10. Inhibition of methane production by commercial cDCE. 

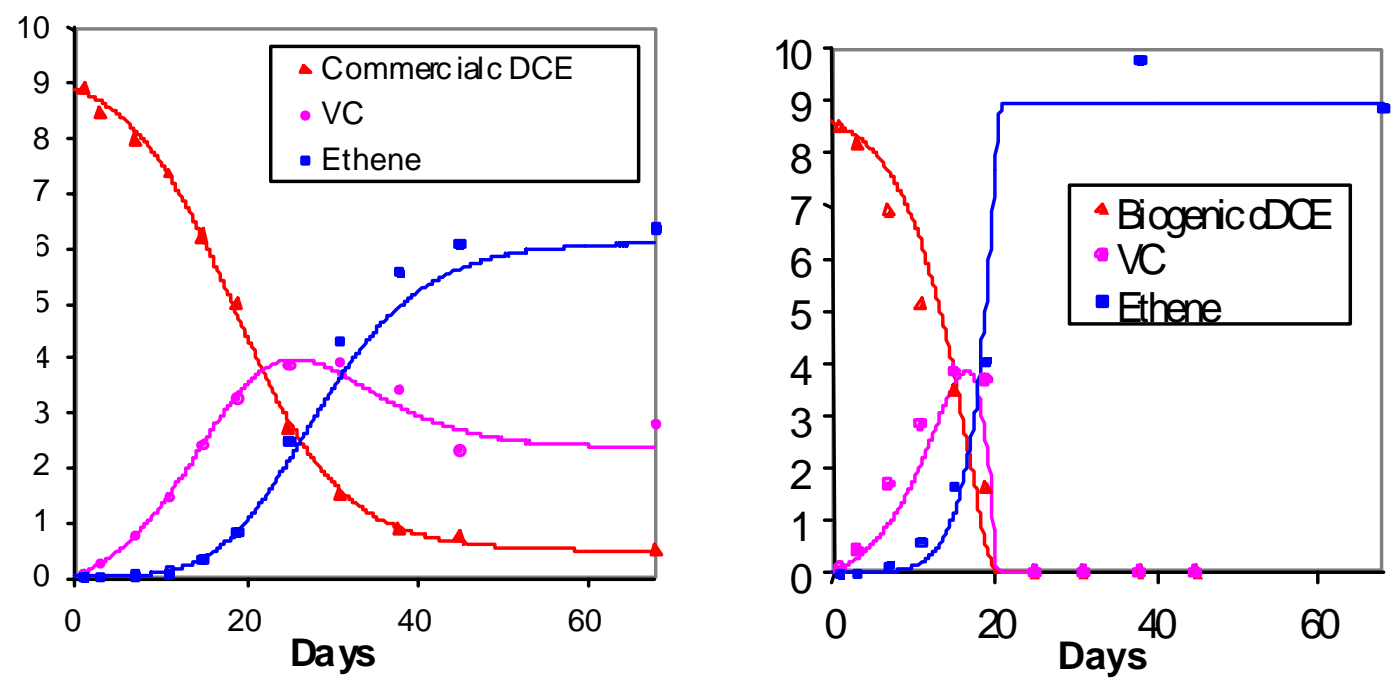

Figure 11. Comparison of the effects of commercial cDCE to biologically generated cDCE. 


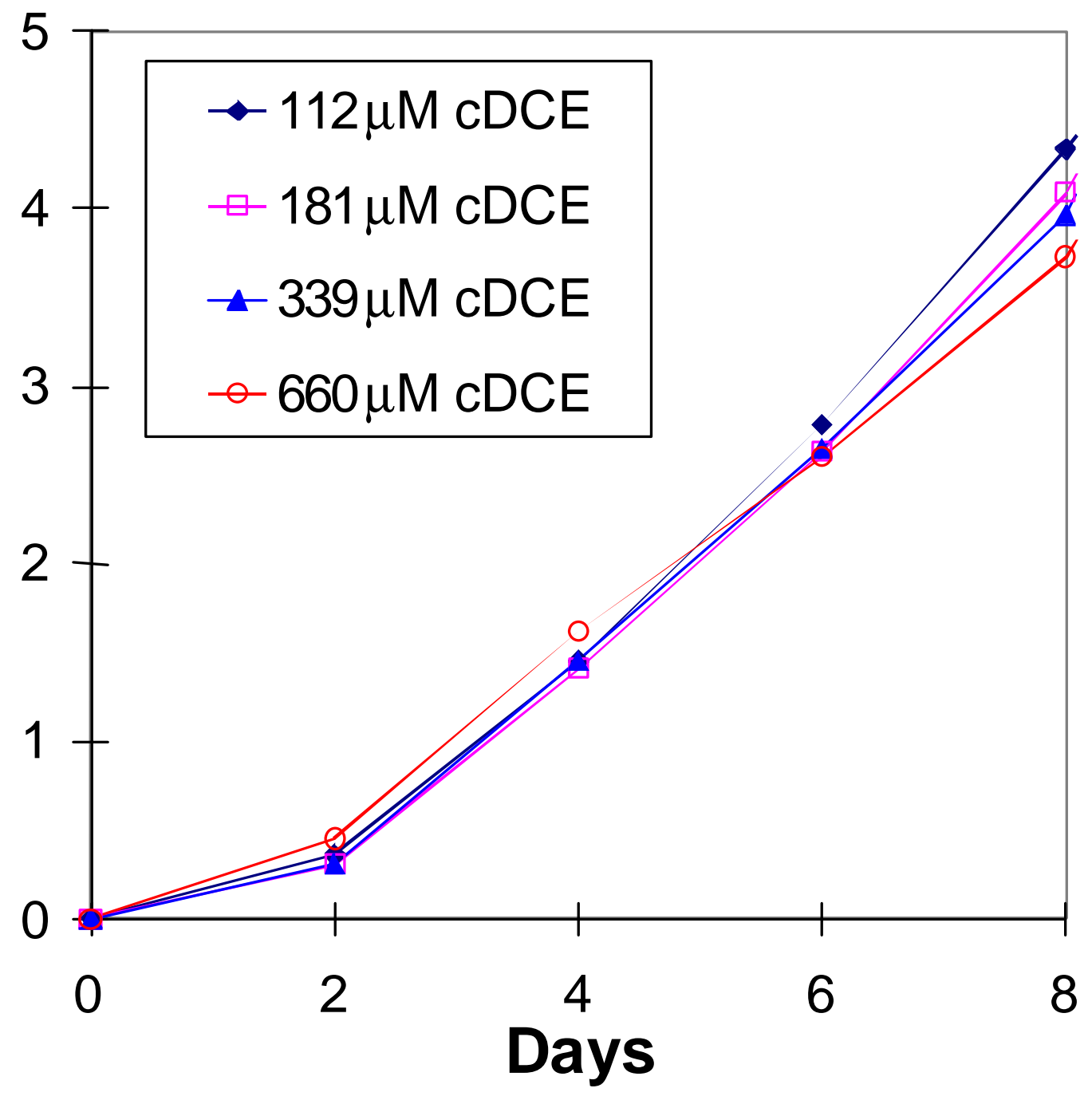

Figure 12. Effect of increasing initial biogenic cDCE concentration on dehalogenation. Total micromoles of dehalogenation in the bottle from $\mathrm{CDCE}$ and $\mathrm{VC}$ are reported. 


\section{ACKNOWLEGMENTS}

This research was partially supported by E.I. duPont de Nemours Inc. through the U.S.

Environmental Protection Agency-sponsored Western Region Hazardous Substance Research Center, Stanford University. 


\section{PROJECT PUBLICATIONS}

Haston, Z. C. 1999. Factors Affecting Growth and Utilization in the Anaerobic Dehalogenation of Chlorinated Ethenes, Ph.D. Dissertation, Stanford University.

Haston, Z. C. and McCarty, P. L. 1999. Chlorinated Ethene Half-Velocity Coefficients (KS) for Reductive Dehalogenation, Environmental Science and Technology, 33(2), 223-226.

Haston, Z. C., Yang, Y., and McCarty, P. L. 2000. Organism Growth and Substrate Utilization Kinetics for the Anaerobic Dehalogenation of cis-Dichloroethene and Vinyl Chloride, submitted for publication .

Rosner B, McCarty P. L., Spormann A. M. 1997: In vitro studies on reductive vinyl chloride dehalogenation by an anaerobic mixed culture. Appl. Environ. Microbiol., 63 (11):41394144.

Yang, Y. and McCarty, P. L 1998. Competition for Hydrogen within a Chlorinated Solvent Dehalogenating Mixed Culture, Environmental Science \& Technology, 32(22), 35913597.

Yang, Y. and McCarty, P. L., 1999. Response to "Comment on 'Competition for Hydrogen within a Chlorinated Solvent Dehalogenating Anaerobic Mixed Culture," Environmental Science \& Technology, 33(12), 2128.

Yang, Y. and McCarty, P. L. 2000. Biomass, Oleate, and Other Possible Substrates for Chloroethene Reductive Dehalogenation, Bioremediation Journal, 4(2) 125-133. 


\section{LITERATURE CITED}

Bagley, D. M. 1998. Systematic Approach for Modeling Tetrachloroethene Biodegradation. Jour. of Environmental Engineering, 124(11): 1076-1086.

Ballapragada, B. S., H. D. Stensel, J. A. Puhakka and J. F. Ferguson. 1997. Effect of Hydrogen on Reductive Dechlorination of Chlorinated Ethenes. Environmental Science and Technology, 31(6): 1728-1734.

Barrio-Lage, G., F. Parsons and R. S. Nassar. 1987. Kinetics of the Depletion of Trichloroethene. Environmental Science \& Technology, 21(4): 366-370.

Barrio-Lage, G., F. Z. Parsons, R. S. Nassar and P. A. Lorenzo. 1986. Sequential Dehalogenation of Chlorinated Ethenes. Environ. Sci. Technol., 20(1): 96-99.

Beeman, R., et al. 1994. A Field Evaluation of In Situ Microbial Reductive Dehalogenation by the Biotransformation of Chlorinated Ethylenes. In R. E. Hinchee, A. Leeson, L. Semprini and S. K. Ong ed., Bioremediation of Chlorinated and Polycyclic Aromatic Hyddrocarbon Compounds, Lewis Publishers, Boca Raton, Florida, pp. 14-27.

Carter, S. R. and W. J. Jewell. 1993. Biotransformation of Tetrachloroethylene By Anaerobic Attached-Films At Low-Temperatures. Water Research, 27(\#4): 607-615.

Corapcioglu, M. Y. and M. A. Hossain. 1991. Estimating Biotransformation Rate Constants for Sequential Reductive Dehalogenation Reactions. Jour. of Environmental Engineering, 117(5): 631-639.

Cord-Ruwisch, R., H. J. Seitz and R. Conrad. 1988. The Capacity of Hydrogenotrophic Anaerobic Bacteria to Compete for Traces of Hydrogen Depends on the REdox Potential of the Terminal Electron Acceptor. Arch. Microbiol., 149: 350-357.

de Bruin, W. P., et al. 1992. Complete Biological Reductive Transformation of Tetrachloroethene to Ethane. Applied and Environmental Microbiology, 58(6): 19962000.

DiStefano, T. D., J. M. Gossett and S. H. Zinder. 1991. Reductive Dechlorination of High Concentrations of Tetrachloroethene to Ethene by an Anaerobic Enrichment Culture in the Absence of Methanogenesis. Appl. Environ. Microbiol., 57(8): 2287-2292.

Dolfing, J. and D. B. Janssen. 1994. Estimates of Gibbs Free Energies of Formation of Chlorinated Aliphatic Compounds. Biodegradation, 5(1): 21-28.

Eaton, A. D., L. S. Clesceri, A. E. Greenberg and M. A. H. Franson ed. 1995. Stanford Methods for the Examination of Water and Wastewater edit. American Public Health Association, Washington D.C.

Fennel, D. E., M. A. Stover, S. H. Zinder and J. M. Gossett. 1995. Comparison of Alternative Electron Donors to Sustain PCE Anaerobic Reductive Dechlorination. In R. E. Hinchee, A. Leeson and L. Semprini ed., Bioremediation of Chlorinated Solvents, Battelle Press, Columbus, pp. 9-16.

Fennell, D. E. and J. M. Gossett. 1998. Modeling the Production of and Competition for Hydrogen in a Dechlorinated Culture. Environmental Science and Technology, 32(16): 2450-2460. 
Fennell, D. E., J. M. Gossett and S. H. Zinder. 1997. Comparison of Butyric Acid, Ethanol, Lactic Acid, and Propionic Acid as Hydrogen Donors for the Reductive Dechlorination of Tetrachloroethene. Environmental Science and Technology, 31(3): 918-926.

Freedman, D. L. and J. M. Gossett. 1989. Biological Reductive Dechlorination of Tetrachloroethylene and Trichloroethylene to Ethylene under Methanogenic Conditions. Applied and Environmental Microbiology, 55(9): 2144-2151.

Gantzer, C. J. and L. P. Wackett. 1991. Reductive Dechlorination Catalyzed by Bacterial Transition-Metal Coenzymes. Environmenal Science and Technology, 25(4): 715-722.

Gerritse, J., et al. 1996. Desulfitobacterium sp. strain PCE1, an anaerobic bacterium that can grow by reductive dechlorination of tetrachloroethene or ortho-chlorinated phenols. Archives of Microbiology, 165(2): 132-40.

Gossett, J. M. 1973. Laboratory Studies in the Resease of Mercury from Waste Ores by WaterLeaching. , : 31 .

Gossett, J. M. 1987. Measurement of Henry's Law Constants for $\mathrm{C}_{1}$ and $\mathrm{C}_{2}$ Chlorinated Hydrocarbons. Environmental Science \& Technology, 21(2): 202-208.

Haston, Z. C. and P. L. McCarty. 1999. Chlorinated ethene half-velocity coefficients (K-s) for reductive dehalogenation. Environmental Science \& Technology, 33(\#2): 223-226.

Holliger, C., G. Schraa, A. J. M. Stams and A. J. B. Zehnder. 1993. A highly purified enrichment culture couples the reductive dechlorination of tetrachloroethene to growth. Applied And Environmental Microbiology, 59(9): 2991-2997.

Holliger, C. and W. Schumacher. 1994. Reductive Dehalogenation as a Respiratory Process. Antonie Van Leeuwenhoek, 66(1-3): 239-246.

Holliger, C., G. Wohlfarth and G. Diekert. 1998. Reductive dechlorination in the energy metabolism of anaerobic bacteria. Fems Microbiology Reviews, 22(\#5): 383-398.

Jablonski, P. E. and J. G. Ferry. 1992. Reductive dechlorination of trichloroethylene by the carbon monoxide-reduced carbon monoxide dehydrogenase enzyme complex from Methanosarcina thermophila. Fems Microbiology Letters, 96: 55-59.

Jeris, J. S. and P. L. McCarty. 1965. Biochemistry of Methane Fermentation Using C14 Tracers. Journal Water Pollution Control Federation, 37: 178-192.

Lovley, D. R. and S. Goodwin. 1988. Hydrogen concentrations as an indicator of the predominant terminal electron-accepting reactions in aquatic sediments. Geochomica et Cosmochimica Acta, 52: 2993-3003.

Magnuson, J. K., et al. 1998. Reductive Dechlorination of Tetrachloroethene to Ethene By 2Component Enzyme Pathway. Applied and Environmental Microbiology, 64(\#4): 12701275.

Maymo-Gatell, X., Y. T. Chien, J. M. Gossett and S. H. Zinder. 1997. Isolation of a Bacterium That Reductively Dechlorinates Tetrachloroethene to Ethene. Science, 276(\#5318): 15681571.

McCarty, P. L. 1964. Anaerobic Waste Treatment Fundamentals, Part III, Toxic Materials and Their Control. Public Works, 95(November): 91-94. 
Mendenhall, W. and T. Sincich. 1992. Statistics for Engineering and the Sciences (3rd ed.). Dellen Publishing Company, San Francisco.

Miller, E., G. Wohlfarth and G. Diekert. 1997. Comparative studies on tetrachloroethene reductive dechlorination mediated by Desulfitobacterium sp. strain PCE-S. Archives of Microbiology, 168(6): 513-9.

Neumann, A., H. Scholz-Muramatsu and G. Dickert. 1994. Tetrachloroethene metabolism of Dehalospirillum multivorans. Archives of Microbiology, 162(4): 295-301.

Neumann, A., G. Wohlfarth and G. Diekert. 1995. Properties of Tetrachloroethene and Trichloroethene Dehalogenase of Dehalospirillum multivorans. Arch. Microbiol, 163: 276-281.

Neumann, A., G. Wohlfarth and G. Diekert. 1996. Purification and characterization of tetrachloroethene reductive dehalogenase from Dehalospirillum multivorans. Journal of Biological Chemistry, 271(28): 16515-9.

Parsons, F. and G. B. Lage. 1985. Chlorinated organics in simulated groundwater environments. Amer. Water Works Assoc., 77: 52-59.

Pontius, F. W. 1992. A Current Look at the Federal Drinking Water Regulations. American Water Works Association Journal, 84(3): 36-50.

Rosner, B. M., P. L. McCarty and A. M. Spormann. 1997. In-Vitro Studies On Reductive VinylChloride Dehalogenation By an Anaerobic Mixed Culture. Applied and Environmental Microbiology, 63(\#11): 4139-4144.

Schink, B. 1985. FEMS Microbiol. Ecol., 31: 63-68.

Scholz-Muramatsu, H., et al. 1995. Isolation and Characterization of Dehalospirillum multivorans gen., sp. nov., a tetrachloroethene-utilizing, strictly anaerobic bacterium. Arch. Microbiol., 163: 48-56.

Scholz-Muramatsu, H., R. Szewzyk, U. Szewzyk and S. Gaiser. 1990. FEMS Microbioilogy Letters, 66: 81-86.

Schumacher, W. and C. Holliger. 1996. The proton/electron ration of the menaquinonedependent electron transport from dihydrogen to tetrachloroethene in "Dehalobacter restrictus". Journal of Bacteriology, 178(8): 2328-33.

Sharma, P. K. and P. L. McCarty. 1996. Isolation and Characterization of a Facultatively Aerobic Bacterium That Reductively Dehalogenates Tetrachloroethene to Cis-1 ;2Dichloroethene. Applied and Environmental Microbiology, 62(\#3): 761-765.

Skeen, R. S., J. W. Gao and B. S. Hooker. 1995. Kinetics of Chlorinated Ethylene Dehalogenation Under Methanogenic Conditions. Biotechnology and Bioengineering, 48(\#6): 659-666.

Smatlak, C. R., J. M. Gossett and S. H. Zinder. 1996. Comparative Kinetics of Hydrogen Utilization for Reductive Dechlorination of Tetrachloroethene and Methanogenesis in an Anaerobic Enrichment Culture. Environ. Sci. Technol., 30: 2850-2858.

Tandoi, V., et al. 1994. Reductive dehalogenation of chlorinated ethenes and halogenated ethanes by a high-rate anaerobic enrichment culture. Environmental Science \& Technology, 28(5): 973-979. 
Terzenbach, D. P. and M. Blaut. 1994. Transformation of tetrachloroethylene to trichloroethylene by homoacetogenic bacteria. Fems Microbiology Letters, 123(1-2): 213-8.

Thauer, R. K., K. Jungermann and K. Decker. 1977. Energy Conservation in Chemotrophic Anaerobic Bacteria. Bacteriological Reviews, 41(1): 100-180.

Tonnaer, H., et al. 1997. In B. C. Alleman and A. Leeson ed., In Situ and On-Site Bioremediation, Battelle Press, Columbus, pp. 591-596.

Vancheeswaran, S., et al. 1998. Transformation of TCE Driven by Orano-Silican Compounds. In Remediation of Chlorinated and Recalcitrant Compounds, Platform Abstracts Battelle, Columbus, Monterey, CA, pp. c6.

Vogel, T. M., C. S. Criddle and P. L. McCarty. 1987. Transformations of Halogenated Aliphatic Compounds. Environmental Science and Technology, 21: 722-736.

Vogel, T. M. and P. L. McCarty. 1985. Biotransformation of Tetrachloroethylene to Trichloroethylene, Dichloroethylene, Vinyl Chloride, and Carbon Dioxide under Methanogenic Conditions. Applied and Environmental Microbiology, 49: 1080-1083.

Wrenn, B. A. and B. E. Rittmann. 1995. A Model for the Effects of Primay Substrates on the Kinetics of Reductive Dehalogenation. Biodegradation, 6: 295-308.

Yang, Y. R. and P. L. McCarty. 1998. Competition For Hydrogen Within a Chlorinated Solvent Dehalogenating Anaerobic Mixed Culture. Environmental Science \& Technology, 32(\#22): 3591-3597. 